\title{
Implication of inflammatory signaling pathways in obesity-induced insulin resistance
}

\author{
Jean-François Tanti ${ }^{1,2 *}$, Franck Ceppo ${ }^{1,2}$, Jennifer Jager ${ }^{1,2+}$ and Flavien Berthou ${ }^{1,2}$ \\ 1 INSERM U1065, Mediterranean Center of Molecular Medicine (C3M), Team "Molecular and Cellular Physiopathology of Obesity and Diabetes", Nice, France \\ ${ }^{2}$ Faculty of Medicine, University of Nice Sophia-Antipolis, Nice, France
}

\author{
Edited by: \\ Tsuguhito Ota, Kanazawa University, \\ Japan \\ Reviewed by: \\ Undurti N. Das, UND LIfe Sciences, \\ USA \\ Marek Bolanowski, Wroclaw \\ Medical University, Poland \\ *Correspondence: \\ Jean-François Tanti, INSERM U1065, \\ Centre Méditerranéen de Médecine \\ Moléculaire, Bâtiment Archimed, \\ 151 , route de St. Antoine de \\ Ginestière, BP 2 3194, 06204, Nice \\ Cedex 3, France. \\ e-mail: tanti@unice.fr \\ ${ }^{\dagger}$ Present address: \\ Jennifer Jager, Division of \\ Endocrinology, Diabetes, and \\ Metabolism, Department of \\ Medicine, Department of Genetics, \\ and The Institute for Diabetes, \\ Obesity, and Metabolism, Perelman \\ School of Medicine at the University \\ of Pennsylvania, Philadelphia, \\ PA, USA.
}

Obesity is characterized by the development of a low-grade chronic inflammatory state in different metabolic tissues including adipose tissue and liver. This inflammation develops in response to an excess of nutrient flux and is now recognized as an important link between obesity and insulin resistance. Several dietary factors like saturated fatty acids and glucose as well as changes in gut microbiota have been proposed as triggers of this metabolic inflammation through the activation of pattern-recognition receptors (PRRs), including Toll-like receptors (TLR), inflammasome, and nucleotide oligomerization domain (NOD). The consequences are the production of pro-inflammatory cytokines and the recruitment of immune cells such as macrophages and T lymphocytes in metabolic tissues. Inflammatory cytokines activate several kinases like IKK $\beta$, mTOR/S6 kinase, and MAP kinases as well as SOCS proteins that interfere with insulin signaling and action in adipocytes and hepatocytes. In this review, we summarize recent studies demonstrating that PRRs and stress kinases are important integrators of metabolic and inflammatory stress signals in metabolic tissues leading to peripheral and central insulin resistance and metabolic dysfunction. We discuss recent data obtained with genetically modified mice and pharmacological approaches suggesting that these inflammatory pathways are potential novel pharmacological targets for the management of obesity-associated insulin resistance.

Keywords: obesity, insulin resistance, inflammation, adipose tissue, pattern-recognition receptors, stress kinases, macrophages

\section{INTRODUCTION}

Obesity is characterized by an excessive adipose tissue expansion due to an increase in nutrients intake and insufficient energetic expenditure. Obesity has dramatically increased worldwide and leads to numerous adverse metabolic disorders including cardiovascular diseases, type 2 diabetes, and some forms of cancer. Insulin resistance is associated with obesity and is a central component of type 2 diabetes, leading to altered glucose and lipid metabolism in adipose tissue, liver, and skeletal muscles. Insulin resistance is characterized by a decrease in insulin signaling mainly in the Insulin Receptor Substrate (IRS)/PI-3-kinase/PKB axis that is responsible for most of the metabolic actions of the hormone (Taniguchi et al., 2006). It is now recognized that a chronic low-grade systemic and local inflammation that develops during obesity could connect obesity to the development of insulin resistance (Gregor and Hotamisligil, 2011). This inflammatory state has been reported in different organs involved in the control of metabolic homeostasis including adipose tissue, liver, endocrine pancreas, hypothalamus, and possibly skeletal muscles. The chronic inflammation is caused by an excess of nutrient intake and has been named metabolic inflammation or metainflammation (Gregor and Hotamisligil, 2011). Several dietary factors including saturated fatty acids and glucose as well as a change in gut microbiota have been proposed as triggers of this metabolic inflammation that involves both metabolic cells, such as adipocytes, and a change in the population of immune cells in metabolic tissues (Lolmede et al., 2011; Bertola et al., 2012; Sun et al., 2012). Hypoxia that develops in adipose tissue could also participate in its inflammation and has been recently involved in insulin resistance of adipocytes (Regazzetti et al., 2009; Wood et al., 2009).

In this review, we will first describe the major mediators that link the excess of nutrients to the production of inflammatory cytokines, focusing on pattern-recognition receptors (PRRs). We will then discuss the intracellular signaling pathways activated by inflammatory mediators and involved in the desensitization of insulin signaling. We will also discuss whether and how the blockade of these mechanisms could improve insulin sensitivity.

\section{IMMUNE SENSORS LINKING NUTRITIONAL STRESS TO OBESITY-INDUCED INFLAMMATION AND INSULIN RESISTANCE TOLL-LIKE RECEPTORS}

Toll-like receptors (TLR) belong to the family of PRRs and play a crucial role in innate immunity by their ability to sense pathogens through the pathogen-associated molecular patterns (PAMPs) 
and to detect tissue injury through the danger-associated molecular patterns (DAMPs) (Mogensen, 2009). TLRs 1/2/4/5/6/11 are plasma membrane proteins whereas TLRs 3/7/8/9 are present in intracellular compartments. Microbial components induce the activation of the TLR signaling through a MyD88 (myeloid differentiation factor)-dependent pathway, except for TLR3, leading to the activation of the transcription factors NF- $\kappa$ B and AP-1 and the production of inflammatory cytokines. Mitogenactivated protein kinases including extracellular signal-regulated kinases (ERK1/2), JNK, and p38 are also activated by TLRs engagement. TLR3 and TLR4 activation also induces an IFN- $\beta$ response through a MyD88-independent but TRIF (TIR domaincontaining adaptor inducing interferon)-dependent pathway (Mogensen, 2009).

Among the different members of the TLR family, several groups have reported a role for TLR2, TLR4 in inflammation and insulin resistance during obesity (Fresno et al., 2011; Könner and Brüning, 2011). Most of the studies focused on TLR4 which is expressed in macrophages, dendritic cells but also in adipocytes, hepatocytes, muscles, and in the hypothalamus. TLR4 expression is increased in obese mice and obese and diabetic patients and negatively correlates with insulin sensitivity (Könner and Brüning, 2011). Recently it has been proposed that during obesity, metabolic endotoxemia contributes to the development of inflammation and metabolic disorders through the activation of TLR4 in metabolic tissues (Figure 1). Metabolic endotoxemia is defined as a moderate increase in circulating lipopolysaccharide (LPS) from Gram-negative bacteria and it develops owing to alterations in the composition of gut microbiota and to an increase in gut permeability (Cani and Delzenne, 2009; Burcelin et al., 2011). Further, high-fat diet could also enhance the translocation of live Gram-negative bacteria from the gut to the adipose

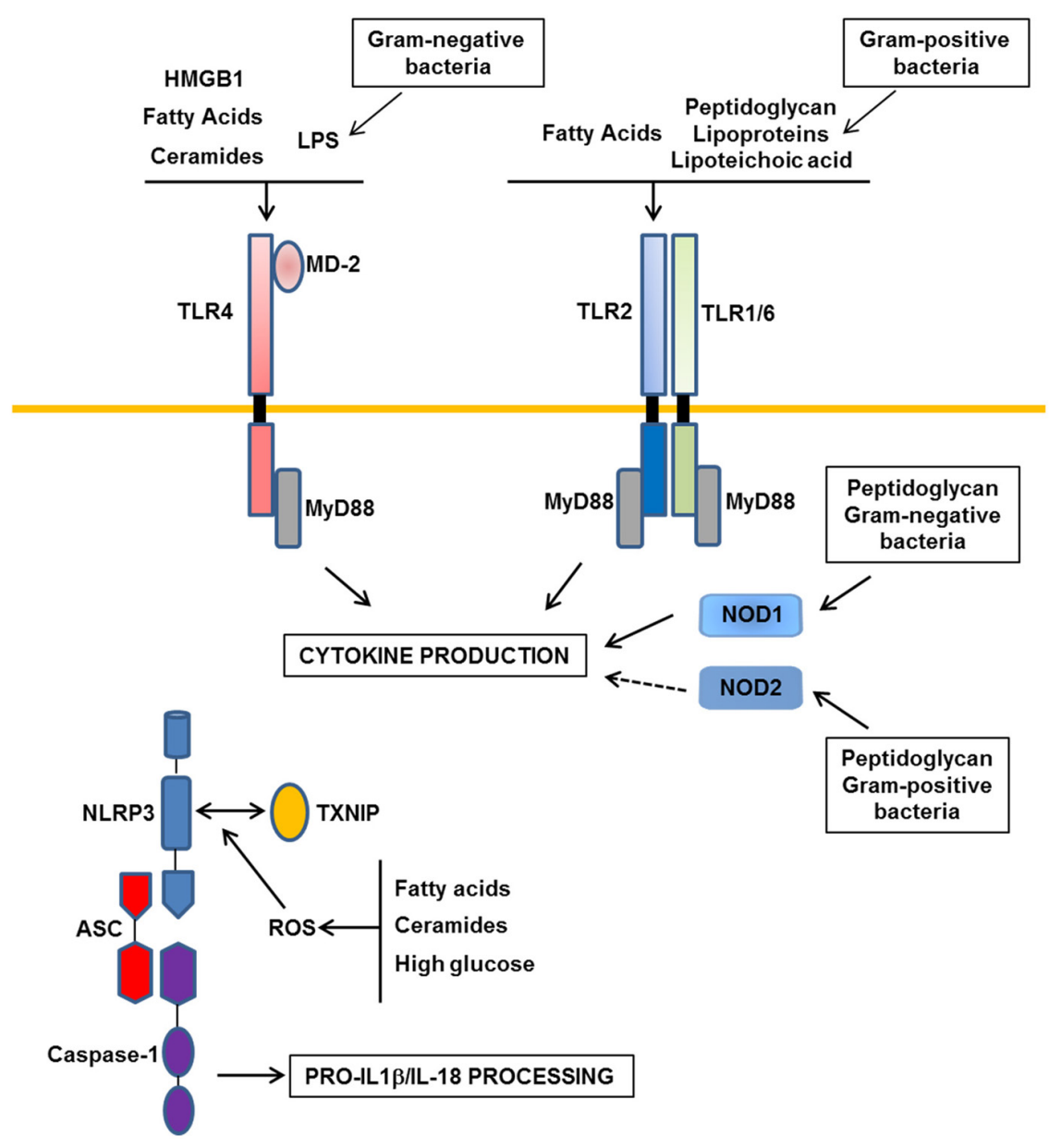

FIGURE 1 | Major Patterns-Recognition Receptors involved in obesity-induced inflammation. In obesity, the moderate increase in LPS derived from gram-negative commensal bacteria activates TLR4 (Toll-like receptors). TLR2 and NOD1/2 (Nucleotide Oligomerization Domain) could be activated by peptidoglycan, lipoproteins, and lipoteichoic acid from gram-negative or -positive commensal bacteria. In addition, nutrients such as saturated fatty acids and their metabolites ceramides could interact with TLR4 or could indirectly activate this receptor through the production of DAMPs such as HMGB1. TLR2 could also be a receptor for saturated fatty acids. Following activation of these receptors, inflammatory cytokines are produced. Among them, IL-1 $\beta$ and IL-18 should be processed in their mature forms by the NLRP3 inflammasome composed of NLRP3, ASC, and caspase-1. ROS production in response to a high level of fatty acids, ceramides, or glucose could trigger the association between TXNIP and NLRP3 leading to the activation of caspase-1 in the inflammasome complex. 
tissue, a process that is dependent, at least partly, on CD14 that acts as a co-receptor with TLR4 to sense LPS (Amar et al., 2011).

Saturated fatty acids are other potential ligands of TLR4 both in adipocytes and macrophages leading to the production of inflammatory cytokines and also ceramides (Shi et al., 2006b; Radin et al., 2008; Fresno et al., 2011; Könner and Brüning, 2011) (Figure 1). TLR4 also mediates the cross-talk between adipocytes and macrophages induced by fatty acids (Suganami et al., 2007b). However, a direct binding of saturated fatty acids to TLR4 has been recently challenged due to LPS contamination (Erridge and Samani, 2009). It is thus possible that saturated fatty acids indirectly interact with TLR4 through fetuin A (Pal et al., 2012). Alternatively, fatty acids might activate TLR4 signaling through the production of endogenous DAMPs such as HMGB1 (HighMobility Group Box1) and/or through ceramides production (Fischer et al., 2007; Li et al., 2011) (Figure 1).

The in vivo pathophysiological importance of TLR4 in obesityinduced inflammation and insulin resistance was investigated by using mice deficient in TLR4 signaling owing to invalidation of TLR4 (TLR4 $4^{-/}$mice) or to a loss-of-function mutation in the Tlr4 gene (C3H/HeJ and C57BL/10ScN) (Table 1). The different studies have reported a mild reduction in inflammation in adipose tissue and liver or in the vasculature (Shi et al., 2006b; Kim et al., 2007; Poggi et al., 2007; Suganami et al., 2007a; Tsukumo et al., 2007; Li et al., 2011; Orr et al., 2012; Ye et al., 2012). The lower inflammation in adipose tissue was linked to a decrease in macrophage infiltration or to a change in macrophage polarization toward a M2 anti-inflammatory phenotype (Shi et al., 2006b; Tsukumo et al., 2007; Davis et al., 2008; Orr et al., 2012). Reduction in inflammation in liver Kupffer cells and in liver parenchymal cells (Li et al., 2011; Ye et al., 2012) was associated with a decrease in hepatic steatosis or with a reduction in the progression from steatosis to non-alcoholic steatohepatitis (Poggi et al., 2007; Tsukumo et al., 2007; Radin et al., 2008; Li et al., 2011; Orr et al., 2012; Ye et al., 2012). In contrast, contradictory results have been obtained concerning the development of obesity. Some studies have reported that $\mathrm{C} 3 \mathrm{H} / \mathrm{HeJ}, 10 \mathrm{ScN}$, or male TLR $4^{-/-}$mice gained less weight on a high-fat diet than their respective controls (Tsukumo et al., 2007; Davis et al., 2008; Radin et al., 2008; Saberi et al., 2009; Orr et al., 2012). This phenotype could be related to a protection against diet-induced leptin or insulin resistance in the hypothalamus in the absence of a functional TLR4 signaling (Kleinridders et al., 2009; Milanski et al., 2009; Könner and Brüning, 2011). However, other studies have described a higher feeding efficiency of the $\mathrm{C} 3 \mathrm{H} / \mathrm{HeJ}$ mice with increased adipose tissue mass and adipocyte hypertrophy (Poggi et al., 2007), an increase in body weight gain and

Table 1 | Phenotype of the different TLR4-deficient mice fed with a high-fat diet.

\begin{tabular}{|c|c|c|c|c|c|c|c|c|c|}
\hline & Genotype & $\begin{array}{l}\% \text { Fat } \\
\text { in diet }\end{array}$ & $\begin{array}{l}\text { Body Weight } \\
\text { gain }\end{array}$ & $\begin{array}{l}\text { Whole-Body } \\
\text { IS }\end{array}$ & $\begin{array}{l}\text { Food } \\
\text { Intake }\end{array}$ & $\begin{array}{l}\text { Adipose } \\
\text { Tissue } \\
\text { inflammation }\end{array}$ & ATM & $\begin{array}{l}\text { Adipose } \\
\text { Tissue IS }\end{array}$ & Steatosis \\
\hline Tsukumo et al. & $\mathrm{C} 3 \mathrm{H} / \mathrm{HeJ}$ & 55 & $\downarrow$ & $\uparrow$ & $=$ & $\downarrow$ & $\downarrow$ & $\uparrow$ & $\downarrow$ \\
\hline Poggi et al. & $\mathrm{C} 3 \mathrm{H} / \mathrm{HeJ}$ & 45 & $=$ & $=$ & $\downarrow$ & $\downarrow$ & $=$ & $\uparrow$ & $\downarrow$ \\
\hline Suganami et al. & $\mathrm{C} 3 \mathrm{H} / \mathrm{HeJ}$ & 60 & $=$ & $\uparrow$ & ND & $\downarrow$ & $=$ & ND & ND \\
\hline Davis et al. & $10 \mathrm{ScN}$ & 60 & $\downarrow$ & $\uparrow$ & ND & $\downarrow \pm$ & $\downarrow$ & ND & ND \\
\hline Radin et al. & $10 \mathrm{ScN}$ & 45 & $\downarrow$ & $=$ & $\downarrow$ & ND & ND & ND & $\downarrow$ \\
\hline Li et al. & $10 \mathrm{ScN}$ & 60 & $\downarrow$ & & $=$ & ND & ND & ND & $\downarrow$ \\
\hline Shi et al. & TLR4 $4^{-/-} \mathrm{F}$ & 60 & $\uparrow$ & $\uparrow$ & $\uparrow$ & $\downarrow$ & $\downarrow$ & ND & ND \\
\hline Shi et al. & $\mathrm{TLR}^{-/-} \mathrm{M}$ & 60 & $=$ & $=$ & $=$ & $\downarrow$ & ND & ND & ND \\
\hline Orr et al. & $\mathrm{TLR}^{-/-}$ & 45 & $\downarrow$ & $=$ & $\downarrow$ & $\downarrow \pm$ & $\uparrow \mathrm{M} 2$ & ND & $\downarrow$ \\
\hline Saberi et al. & $\mathrm{TLR}^{-/-}$ & No data & $\downarrow$ & ND & ND & ND & ND & ND & ND \\
\hline Ding et al. & $\mathrm{TLR}^{-/-} \mathrm{LDLR}^{-/-}$ & 35.5 & $=$ & $=$ & $=$ & $=$ & $=$ & ND & ND \\
\hline Kim et al. & $\mathrm{TLR}^{-/-}$ & 60 & $=$ & ND & ND & ND & ND & ND & ND \\
\hline Saberi et al. & BMT-10ScN & No data & $=$ & $\uparrow$ & $=$ & $\downarrow$ & $\downarrow$ & $\uparrow$ & $\downarrow$ \\
\hline Orr et al. & BMT-TLR4-/- & 45 & $=$ & $=$ & ND & $\downarrow$ & $\uparrow \mathrm{M} 2$ & ND & $=$ \\
\hline Coenen et al. & BMT-TLR4-/- & 41 & $=$ & $=$ & ND & $=$ & $=$ & ND & ND \\
\hline
\end{tabular}

C3H/HeJ: Mice harboring a spontaneous missense mutation in the third exon in the TIr4 gene leading to a loss-of-function of TLR4.

$10 \mathrm{ScN}$ : Mice that display a spontaneous mutation resulting in $7 \mathrm{~kb}$ deletion in the TIr4 gene that results in absence of both mRNA and protein expression.

TLR4-1-: Mice with a knockout of the TIr4 gene. F female. M male.

BMT-10ScN: Transplantation of bone marrow from $10 \mathrm{SCN}$ mice into C57BL6 mice.

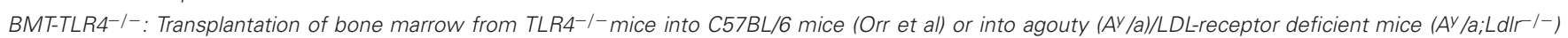

(Coenen et al.).

IS: Insulin Sensitivity.

ATM: Adipose tissue macrophages.

M2: macrophages with a M2 anti-inflammatory polarization.

ND: not determined in the study. 
adipose tissue mass in female TLR4 ${ }^{-/-}$mice (Shi et al., 2006b) or no protection against obesity in male TLR $4^{-/}$mice (Shi et al., 2006b; Kim et al., 2007). The majority of the studies have reported a reduction in the insulin resistance, at least in adipose tissue and liver (Shi et al., 2006b; Suganami et al., 2007a; Tsukumo et al., 2007; Poggi et al., 2007; Davis et al., 2008). However, some of them, mainly concerning male TLR $4^{-/-}$, did not show any improvement in whole-body insulin sensitivity (Shi et al., 2006b; Radin et al., 2008; Ding et al., 2012; Orr et al., 2012).

Different studies have investigated the consequences of TLR4 invalidation specifically in immune cells by transplantation of bone marrow from TLR4-deficient mice into wild-type recipients. In one study, mice developed obesity but with less inflammation and insulin resistance in adipose tissue and liver and no change in muscles (Saberi et al., 2009). In contrast, two other studies using the same experimental strategy but in different genetic backgrounds, failed to observe any improvement in insulin resistance despite a reduction in adipose tissue inflammation and/or a shift in adipose tissue macrophage polarization toward a M2 anti-inflammatory state (Coenen et al., 2009; Orr et al., 2012).

In summary, the consequences on weight gain and insulin resistance are different depending on the genetic background, the sex of the mice, the duration, and the lipid composition of the diet. In this regard, the percentage of saturated lipids in the diet could be important since the protection against insulin resistance seemed to occur selectively when the diet contained a high level of saturated lipids (Davis et al., 2008). It remains to be determined whether the activation of TLR4 signaling by a saturated fat diet is due to a direct action of fatty acids on TLR4 or to an indirect effect through the production of endogenous DAMPs or through the modification of the gut microbiota leading to an increase in circulating LPS. Further, clarification is needed for the respective contribution of TLR4 signaling in hematopoietic vs. non-hematopoietic compartment to the development of insulin resistance. Of note, the analysis of the metabolic phenotype of the TLR4-deficient mice could be complicated due to the potential compensatory increase in TLR2 expression (Ding et al., 2012).

TLR2 detects lipoproteins, lipoteichoic acid, and peptidoglycan from gram-positive bacteria and dimerizes with TLR1 and TLR6 (Mogensen, 2009). TLR2 has a broad pattern of expression and besides its expression in immune cells, is also expressed in insulin sensitive cells and islets (Ehses et al., 2010). A role for TLR2 in the metabolic complications of obesity was suggested by its increased level in different metabolic tissues of obese mice and patients and in circulating monocytes of type 2 diabetic patients (Fresno et al., 2011; Könner and Brüning, 2011). Like TLR4, TLR2 could be a sensor for saturated fatty acids mediating their pro-inflammatory effects in adipose tissue and macrophages and participating in the development of insulin resistance in cultured myotubes or adipocytes (Fresno et al., 2011; Könner and Brüning, 2011). However, as for TLR4, a direct activation of TLR2 by saturated fatty acids has been questioned owing to possible contamination by LPS (Erridge and Samani, 2009). Thus, both TLR4 and TLR2 could participate in the sensing of abnormal levels of nutrients, especially fatty acids and in the detection of gut microflora modification in obesity (Figure 1). Cooperation between these two TLRs might be involved since
TLR4 activation increases the synthesis of TLR2 in adipocytes. This overlapping function could explain the similar metabolic phenotype of TLR4 and TLR2 deficient mice. Indeed, invalidation of TLR2 improved diet-induced insulin resistance and inflammation of adipose tissue, liver, or muscles (Caricilli et al., 2008; Kuo et al., 2011; Ehses et al., 2010 \#3013, Himes and Smith, 2010 \#3010). Further, TLR2 signaling is involved in diet-induced pancreatic islet inflammation and beta-cell dysfunction (Ehses et al., 2010). TLR2 knockout mice have also a reduced adiposity (Ehses et al., 2010; Himes and Smith, 2010; Kuo et al., 2011) suggesting that the lack of TLR2 signaling could decrease lipid uptake or increase lipid oxidation in different tissues. Whether the effect of TLR2 activation on lipid metabolism is direct or the consequence of an inflammatory state remains to be clarified. However, the reported interaction between activated TLR2 and CD36, a transporter of fatty acids, supports a role for TLR2 signaling in fatty acids uptake in metabolic tissues (Triantafilou et al., 2006).

Although the findings discussed above support a protective role of TLR2 inactivation in the context of obesity, a recent study reported that TLR2 knockout mice had a phenotype reminiscent of metabolic syndrome even on low-fat diet. In this setting, it was demonstrated that the gut microbiota was responsible for the development of insulin resistance (Caricilli et al., 2011). This finding illustrates the concept that complex interactions between environment, gut microbiota, and the genetic of the host drive the metabolic phenotype (Nicholson et al., 2012). In this regard, a specific environmental condition and the innate immune system may have shaped a harmful gut microbiota that overcomes the protective effect of the genetic deficiency in TLR2. Alternatively the loss of TLR in immune cells may alter gut microbiota leading to the development of inflammation, obesity, and insulin resistance as described for mice lacking TLR5 (Vijay-Kumar et al., 2010), a TLR highly expressed in the intestinal mucosa and involved in the detection of bacterial flagellin (Mogensen, 2009).

\section{INFLAMMASOME AND NOD}

Nucleotide oligomerization domain (NOD) 1 and 2 are intracellular proteins that recognize cell wall peptidoglycan moieties from gram-negative or gram-positive bacteria, respectively (Mogensen, 2009). NOD proteins have recently emerged as immune sensors involved in inflammation-induced insulin resistance (Figure 1). Peptidoglycan-induced activation of NOD1 in adipocytes or hepatocytes (Schertzer et al., 2011; Zhao et al., 2011) and NOD2 in muscle cells (Tamrakar et al., 2010) trigger insulin resistance through the production of inflammatory mediators and the activation of MAP kinases signaling leading to desensitization of IRS1 function. Injection of specific NOD1 ligand in mice promoted adipose tissue inflammation and induced whole-body insulin resistance with a strong decrease in insulin action in the liver. NOD2 ligand injection caused a milder insulin resistance and preferentially in muscles (Schertzer et al., 2011). NOD1-deficient mice, but not NOD2, were protected against glucose intolerance and diabetes induced by a high-fat diet (Amar et al., 2011). These studies demonstrate the ability of NOD activation to induce insulin resistance and support 
the implication of NOD1 in the control of metabolic diseases through the sensing of components from gram-negative bacteria (Figure 1).

Inflammasomes are multi-protein complexes composed of three proteins: the nucleotide-binding domain leucine-rich repeat (NLR) protein, the adaptor protein ASC (apoptosis-associated speck-like protein containing a CARD) and the caspase-1. Four different inflammasomes have been identified so far namely NLRP1, NLRP3, NLRC4, and AIM2. Pathogen and dangerassociated signals activate inflammasomes leading to the processing of IL-1 $\beta$ and IL-18 by caspase- 1 (Mogensen, 2009). It is recognized that IL- $1 \beta$ is one of the main cytokines implicated in the desensitization of insulin signaling (Lagathu et al., 2006; Jager et al., 2007) and its genetic invalidation protects mice against diet-induced insulin resistance (Stienstra et al., 2010; Wen et al., 2011). Pharmacological inhibition of IL-1 $\beta$ signaling by the IL-1 receptor antagonist anakinra, mitigates inflammation, and improves glycemic control in type 2 diabetic patients (Larsen et al., 2007). With this in mind, several groups have investigated the implication of inflammasome activation in insulin resistance.

The expression of NLRP3 and caspase- 1 is increased in adipose tissue of obese mice, overweight subjects, or obese individuals with type 2 diabetes (Stienstra et al., 2010; Koenen et al., 2011; Vandanmagsar et al., 2011). The identity of cells within the adipose tissue, in which the NLRP3 inflammasome is activated, remains controversial. Two studies reported an expression and activation mainly in adipose tissue macrophages with a low expression in adipocytes whereas Stienstra et al. found an important contribution of adipocytes (Stienstra et al., 2010; Vandanmagsar et al., 2011; Wen et al., 2011). However, invalidation of different components of the NLRP3 inflammasome (NLRP3, ASC, caspase-1) univocally protected the mice against high-fat diet-induced inflammation and insulin resistance. This phenotype was associated with a reduced expression of IL-1 $\beta$ in adipose tissue and a reduced level of circulating IL-18 (Stienstra et al., 2010; Vandanmagsar et al., 2011; Wen et al., 2011). The lack of the NLRP3 inflammasome had consequences on the subset of immune cells within the adipose tissue. The number of M2 anti-inflammatory macrophages was increased in subcutaneous adipose tissue (SAT) and the activation of pro-inflammatory macrophages was dampened in visceral adipose tissue (VAT). In parallel, the number of naive $\mathrm{CD}^{+}$and $\mathrm{CD}^{+}{ }^{+} \mathrm{T}$ cells was increased in SAT and the amount of effector memory $\mathrm{CD}^{+}$and $\mathrm{CD}^{+} \mathrm{T}$ cells was decreased in VAT (Vandanmagsar et al., 2011). These findings suggest a model whereby the NLRP3 inflammasome-dependent production of IL- $1 \beta$ and IL-18 by adipose tissue macrophages favors macrophage- $\mathrm{T}$ cell activation leading to a sustained inflammation of adipose tissue (Vandanmagsar et al., 2011). Besides its role in the control of adipose tissue inflammation, inflammasome activation in adipocytes could limit energy expenditure, fat oxidation, and adipogenesis as revealed by the phenotype of the caspase $1^{-/}$mice (Stienstra et al., 2010, 2011). In addition to adipose tissue, activation of NLRP3-inflammasome in other tissues such as pancreatic islets has been reported (Zhou et al., 2010).
These findings strongly support a model whereby danger signals generated in obesity are detected by the NLRP3inflammasome that in turn promotes inflammation and the dysfunction of different organs involved in the control of glucose and lipid homeostasis (Figure 1). The identity of the danger signals that activate the NLRP3 inflammasome in obesity remains ill-defined. However, the observation that the NLRP3 inflammasome is activated by fatty acids and ceramides suggests that the lipotoxic environment in obesity might trigger its activation (Vandanmagsar et al., 2011; Wen et al., 2011). However, the NLRP3 inflammasome can be activated by other molecules such as ATP, glucose, oxidized LDL, uric acid, and crystals of cholesterol. Since all of them are elevated in obesity, their respective contributions to the activation of inflammasome deserve further investigation. The common feature of these danger signals is their ability to increase ROS production that is prerequisite for NLRP3 inflammasome activation (Tschopp and Schroder, 2010). Thus, the activation of NLRP3 inflammasome in obesity might be related to the oxidative stress that develops in the different metabolic tissues. How NLRP3 inflammasome is activated by ROS is not completely understood but the thioredoxininteracting protein (TXNIP) has recently emerged as a potential link with the demonstration of its binding with NLRP3 in a ROS sensitive manner leading to NLRP3 inflammasome activation (Zhou et al., 2010) (Figure 1). This function might explain the similar phenotype between TXNIP- and NLRP3-deficient mice when fed a high-fat diet (Zhou et al., 2010). Further TXNIP might also connect organelle stress, such as reticulum endoplasmic stress, to NLRP3 inflammasome activation (Oslowski et al., 2012).

All together, these findings render the NLRP3 inflammasome as an attractive pharmacological target against the complications of obesity. In this multi-proteins complex, the easiest target is the caspase- 1 since inhibitors already exist. The caspase- 1 inhibitor Pralnacasan reduced body weight and improved insulin sensitivity of genetically obese $o b / o b$ mice (Stienstra et al., 2010). However, one important caveat for the treatment of a chronic disease such as diabetes is that caspase- 1 is involved in different inflammasome complexes and its inhibition may reduce the ability to fight infection.

Despite the potential role of the NLRP3 inflammasome in obesity-induced inflammation and insulin resistance, it remains to determine whether its activation is a primary event in the disease that drives the inflammation. Further, the relative contribution of NLRP3 inflammasome to the development of inflammation in the metabolic tissues and in the different subset of cells of these tissues should be clarified. The role of other inflammasome complexes also deserves investigation since ablation of NLRP3 markedly reduced but did not totally abrogate caspase-1 activation in adipose tissue or liver of obese mice (Vandanmagsar et al., 2011). Finally, other caspase- 1 substrates besides IL- $1 \beta$ and IL-18 might be involved in the deleterious effect of inflammasome activation on metabolic control. In this regard, the transcription factors SREBPs are activated by caspase-1(Gurcel et al., 2006) and it was recently shown that SREBP-1a regulated the expression of inflammasome components in macrophages (Im et al., 2011). Thus, a feed-forward loop involving caspase- 1 activation 
and SREBP might link lipid metabolism to the inflammasome activation in obesity.

In conclusion, it is now recognized that the immune sensors described above (TLR, NOD, inflammasome) and others such as the pathogen-sensing kinase (PKR) (Nakamura et al., 2010) participate in the development of the metabolic inflammation. As recently discussed by Gregor and Hotamisligil in an outstanding review (Gregor and Hotamisligil, 2011), it is possible that in obesity the levels of nutrient intake may rise enough to stimulate pathogen- and danger-sensing pathways ultimately leading to the activation of immune cells in the different metabolic tissues. In other words, the organism, in overfeeding situation, recognizes the nutrients as harmful biological molecules and activates pathways that are usually engaged by pathogen or endogenous danger signals. In addition, modification of the gut microbiota and of the intestinal permeability in obesity may fuel the organism with inflammatory molecules such as LPS and other bacterial antigens or favor the translocation of commensal bacteria within metabolic tissues (Cani and Delzenne, 2009; Amar et al., 2011; Nicholson et al., 2012). As a consequence, inflammatory cytokines are overproduced and they activate different signaling pathways in metabolic cells that desensitize insulin signaling and alter the expression of proteins involved in glucose transporter trafficking (Kaddai et al., 2009).

\section{INFLAMMATORY SIGNALING PATHWAYS INVOLVED IN THE DESENSITIZATION OF INSULIN ACTION \\ THE SOCS PROTEINS}

The Suppressor of cytokine signaling (SOCS) protein family also named Janus family kinase-binding (JAB) proteins or SSI (signal transducer and activator of transcription induced Stat inhibitor) includes eight members (SOCS1-7 and CIS), which possess a SH2 domain, and a SOCS-box domain controlling the degradation of interacting proteins. They are induced by several inflammatory cytokines and are involved in a negative feedback loop leading to the termination of cytokines action. At the molecular level, the SOCS proteins interact with the tyrosine kinases Janus-activated kinases (JAK) or directly with the receptor of some cytokines, thus blocking the tyrosine phosphorylation of the transcription factors STAT for review see Lebrun and Van Obberghen (2008). Several cellular studies have demonstrated that SOCS negatively regulate the signaling pathway of hormones including leptin and insulin. In this regard, SOCS3 is induced by leptin and insulin and is involved in a negative feedback loop and in a cross-down regulation (Emanuelli et al., 2000; Lebrun and Van Obberghen, 2008; Benomar et al., 2009). SOCS1, SOCS6, and SOCS7 are also involved in the desensitization of insulin signaling. SOCS3 inhibits insulin signaling by a direct binding through its $\mathrm{SH} 2$ domain with the juxtamembrane phosphotyrosine 960 on the insulin receptor, thus preventing the interaction of IRS1 and 2 with the receptor (Figure 2). SOCS1 interacts with the catalytic domain of the insulin receptor which contains an interaction motif for IRS2, blocking thus more selectively the tyrosine phosphorylation of IRS2. SOCS1 and SOCS6 also inhibit the tyrosine kinase activity of the insulin receptor. It has also been shown that SOCS proteins interact with the tyrosine phosphorylated IRS1 and IRS2 resulting in their ubiquitination and degradation by the proteasome (Lebrun and Van Obberghen, 2008) (Figure 2).

In obesity, inflammation leads to an up-regulation of SOCS proteins in hypothalamus, liver, muscles, and adipose tissue (Rieusset et al., 2004; Lebrun and Van Obberghen, 2008). A causal role for the up-regulation of SOCS proteins in the development of insulin resistance has been investigated in metabolic tissues. Overexpression of SOCS1 or SOCS3 in mouse liver or adipose tissue reduced the expression of IRS1 or IRS2 as well as their tyrosine phosphorylation induced by insulin. As a consequence insulin resistance developed in those tissues, as well as systemic insulin resistance for the overexpression in liver (Ueki et al., 2005; Shi et al., 2006a). Unexpectedly, overexpression of SOCS3 in adipose tissue protected the mice against systemic insulin resistance when fed a high-fat diet owing to a decrease in adipocyte hypertrophy (Shi et al., 2006a). Overexpression of SOCS3 in muscle exacerbated diet-induced obesity and insulin resistance but this effect was not due to a decreased insulin signaling but to an alteration in muscle integrity leading to a reduction in locomotor activity and energy expenditure (Lebrun et al., 2009).

The inhibition of SOCS proteins might thus be useful to prevent the development of obesity-induced insulin resistance. In agreement with such a possibility, heterozygous SOCS3 $\left(\mathrm{SOCS}^{+/-}\right)$mice or mice with targeted invalidation of SOCS3 in the central nervous system (CNS) were protected against dietinduced obesity and associated insulin resistance (Howard et al., 2004; Mori et al., 2004; Kievit et al., 2006). This phenotype was explained by increased leptin sensitivity and possibly by an effect on insulin action for the SOCS3 ${ }^{+/-}$mice (Howard et al., 2004). In the same way, targeted invalidation of SOCS3 in adipose tissue or in muscles protected mice against obesity-induced insulin resistance (Jorgensen et al., 2012; Palanivel et al., 2012). SOCS7-deficient mice also displayed improved glucose tolerance and insulin sensitivity (Banks et al., 2005). However, several considerations should be taken into account before inhibiting SOCS proteins for therapeutic purpose. First, some SOCS proteins positively regulate insulin action as demonstrated by the improved insulin sensitivity of SOCS6-overexpressing mice (Li et al., 2004). Second, given that SOCS proteins negatively regulate the signaling of inflammatory cytokines, their chronic inhibition might exacerbate inflammation that could counterbalance its beneficial effect on insulin sensitivity. This dual action of SOCS proteins is well-illustrated by differential effects of short- and long-term invalidation of SOCS1 or SOCS3 in liver. Short-term invalidation by antisense oligonucleotides in obese and diabetic $d b / d b$ mice improved hepatic steatosis with a mild reduction in insulin resistance (Ueki et al., 2005). In contrast, while targeted deletion of SOCS3 in liver-enhanced liver insulin sensitivity on chow diet, it accelerated the onset of high-fat dietor age-induced insulin resistance with an increased inflammation in liver (Torisu et al., 2007; Sachithanandan et al., 2010). This dual action is not restricted to SOCS3, since SOCS1 in immune cells limited the metabolic inflammation in liver and perhaps adipose tissue (Sachithanandan et al., 2011). Thus, the beneficial effect of SOCS1-deletion on insulin sensitivity 


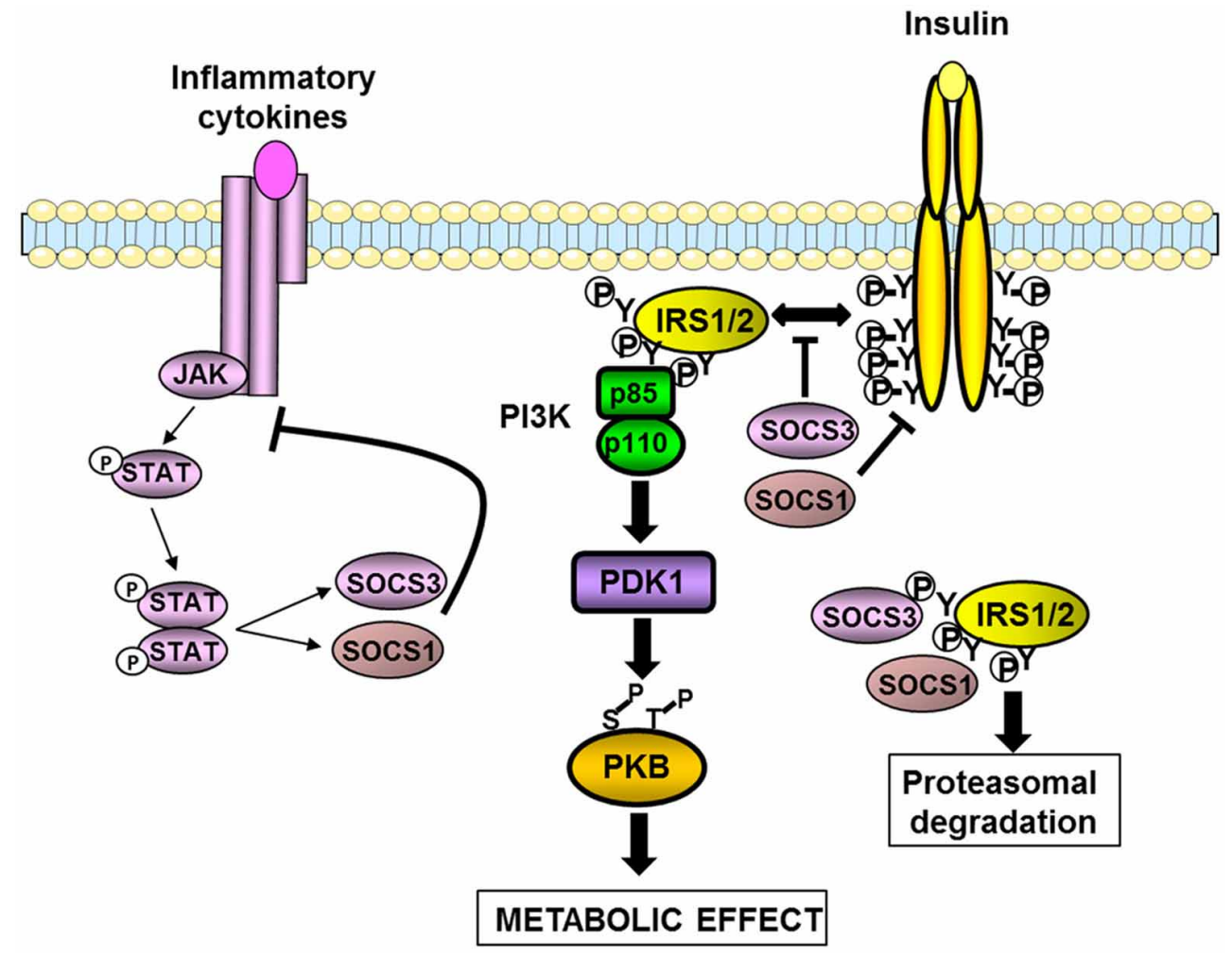

FIGURE 2 | Inhibition of insulin signaling pathway by SOCS1 and SOCS3. SOCS1 and SOCS3 are induced by cytokines and involved in a negative feed-back loop. SOCS1 and SOCS3 also inhibit insulin signaling by different mechanisms. They interfere with the binding between the insulin receptor and IRS1/2 proteins. SOCS1 also inhibits the tyrosine kinase activity of the insulin receptor. Both SOCS1 and SOCS3 can interact with the tyrosine-phosphorylated IRS proteins leading to their degradation by the proteasome. The resulting effect is a decrease in the insulin-induced activation of the IRS1/2-PI3K-PKB axis leading to a reduction in the metabolic effects of insulin. was only visible when SOCS1-deficient mice were crossed with interferon-gamma- or RAG2-deficient mice to limit inflammation. Of note, this beneficial effect was seen on chow diet (Jamieson et al., 2005; Emanuelli et al., 2008b) but was lost on a high-fat diet when the inflammation is enhanced (Emanuelli et al., 2008b). Further, SOCS2-deficient mice were protected against diet-induced hepatic steatosis probably due to an increase in the lipid mobilizing effect of growth hormone. However, this beneficial effect was overridden by a hyperproduction of inflammatory mediators by the resident macrophages leading to a higher level of inflammation in liver and adipose tissue and the worsening of insulin resistance (Zadjali et al., 2012).

In summary, it appears to date that SOCS3 is mainly involved in the regulation of energy balance through the down-regulation of leptin signaling whereas several SOCS such as SOCS1/3/6/7 are involved in the regulation of the insulin sensitivity. Since SOCS proteins contribute to the development of diet-induced obesity and insulin resistance, their targeting could be open new avenues for the treatment of metabolic disorders. However, careful examination of the balance between pro-inflammatory and insulin sensitizing effects of future inhibitors of SOCS proteins will be needed.

\section{THE IKK $\beta / N F-K B$ AND JNK PATHWAYS IN INFLAMMATORY CYTOKINES PRODUCTION AND INSULIN RESISTANCE}

The activity of both IKB-kinase $\beta$ (IKK $\beta$ ) and JNK is elevated in metabolic tissues in obesity, and these kinases are important nodes in the production of inflammatory mediators and in the desensitization of insulin signaling (Tanti and Jager, 2009; Solinas and Karin, 2010; Donath and Shoelson, 2011). JNK and IKK $\beta$ are activated downstream of immune sensors such as TLRs and participate in the production of inflammatory cytokines via the transcription factors $\mathrm{AP}-1$ and $\mathrm{NF}-\kappa \mathrm{B}$ respectively (Figure 3). Many of the produced inflammatory cytokines are able to activate these two kinases leading to a feed-forward amplification loop (Donath and Shoelson, 2011; Gregor and Hotamisligil, 2011). Another important activator of these kinases is the endoplasmic reticulum (ER) stress (Figure 3).

ER stress occurs when the synthesis capacity of the ER is exceeded. In this case, the unfolded protein response (UPR) is activated in order to restore ER homeostasis. Three pathways are involved in the UPR, namely PERK (PKR-like eukaryotic initiation factor 2a), IRE-1 (inositol requiring enzyme 1), and ATF6 (activating transcription factor 6) pathways. If these mechanisms fail to restore proper ER homeostasis, cells undergo apoptosis (Xu et al., 2005). In a pioneer study, Hotamisligil and colleagues 


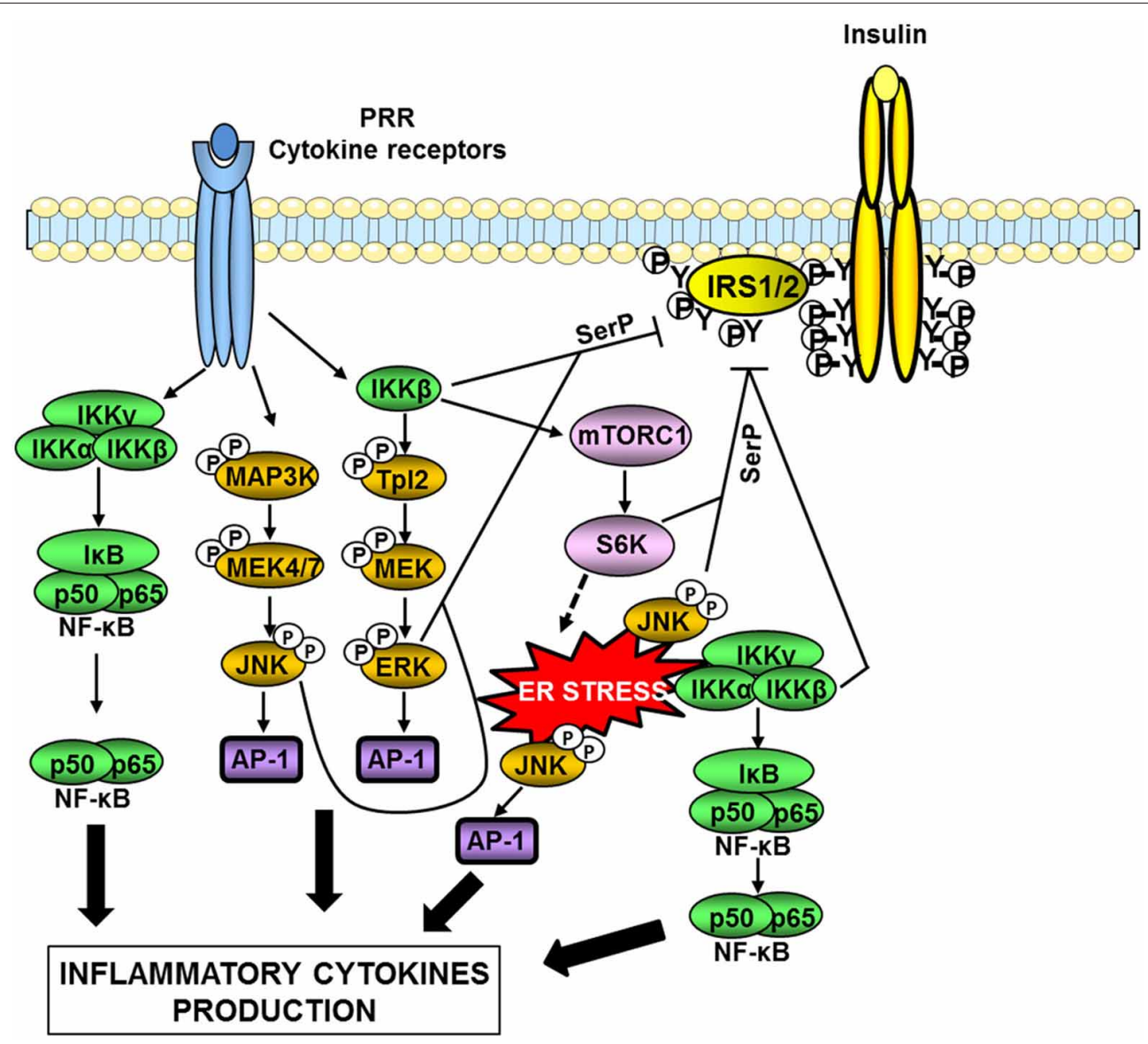

FIGURE 3 | Serine kinases involved in obesity-induced inflammation and insulin resistance. In obesity, a network of serine kinases is activated including IKK $\beta$, JNK, and ERK1/2. JNK and IKK $\beta$ are activated downstream of pattern-recognition receptors (PRRs) such as TLRs or by ER stress. IKK $\beta$ is also involved in the activation of the Tpl2/ERK pathway. These pathways participate in the production of inflammatory cytokines via the transcription factors AP-1 and NF-kB. Many of the produced inflammatory cytokines are able to activate these kinases leading to a feed-forward amplification loop. JNK and ERK1/2 are involved in the desensitization of insulin signaling through phosphorylation of IRS1/2 on inhibitory serine sites (SerP). IKK $\beta$ can directly phosphorylate IRS1/2 on serine sites but can also act indirectly through activation of mTORC1/S6 kinase. Over-activation of the mTORC1/S6K pathway could promote ER stress leading to an amplification loop.
(Ozcan et al., 2004) have demonstrated that ER stress developed in liver and adipose tissue during obesity owing to nutrient overload and participated in the onset of insulin resistance. Several recent reviews have discussed in details the mechanisms linking ER stress to obesity-induced inflammation, insulin resistance, and alterations in tissue metabolism (Cnop et al., 2011; Gregor and Hotamisligil, 2011; Flamment et al., 2012). The activation of IKK $\beta / N F-\kappa B$ and JNK by the IRE- 1 arm of the UPR is one of these mechanisms (Gregor and Hotamisligil, 2011).

At the molecular level, one important mechanism by which IKK $\beta$ and JNK attenuate insulin signaling is the phosphorylation of IRS proteins on inhibitory serine phosphorylation sites (Figure 3). The mechanism by which IRS phosphorylation regulates insulin signaling is complex and described in details in recent reviews (Gual et al., 2005; Boura-Halfon and Zick, 2009; Tanti and Jager, 2009; Copps and White, 2012). In physiological condition, insulin induces a time-controlled phosphorylation of both positive and inhibitory serine sites in IRS1 and IRS2 in order to ensure the fine tuning of IRS tyrosine phosphorylation that is necessary for the propagation of insulin action (Tanti and Jager, 2009; Copps and White, 2012). Since our pioneer study (Tanti et al., 1994), it is now admitted that during obesity, activation of inflammatory, and stress kinases such as JNK and IKK is responsible for an uncontrolled phosphorylation of IRS on inhibitory serine sites resulting in a decrease in IRS tyrosine phosphorylation and a desensitization of insulin signaling (Boura-Halfon and Zick, 2009; Tanti and Jager, 2009). It is noteworthy that JNK seems more involved in the direct IRS serine phosphorylation than IKK $\beta$ (Tanti and Jager, 2009). IKK $\beta$ activation could promote IRS1 serine phosphorylation through activation of TSC1/TSC2/mTORC1/S6 Kinase-1 pathway leading to inhibitory IRS1 serine phosphorylation by S6K1 (Lee et al., 2008). Of note, activation of mTORC1 by IKK $\beta$ could be also involved in feed-forward mechanism induced by inflammatory cytokines to promote ER stress since over-activation of mTORC1 has been linked to the development of ER stress (Ozcan et al., 2008) 
(Figure 3). In addition, activation of the IKK $\beta / \mathrm{NF \kappa B}$ pathway increases the expression of PTP1B, a tyrosine phosphatase that dephosphorylates IRS1 (Zabolotny et al., 2008).

Several in vivo studies in mice have demonstrated the importance of the IKK $\beta / N F-\kappa B$ and JNK pathways in the development of insulin resistance (Figures 4, 5). Heterozygous IKK $\beta$ and whole-body JNK1-deficient mice were partially protected against diet-induced insulin resistance (Yuan et al., 2001; Hirosumi et al., 2002). JNK2 could also play a role in insulin resistance but to a lesser extent (Tuncman et al., 2006). A cell-autonomous mechanism that involves the negative regulation of IRS1 function by serine phosphorylation was implicated in the regulation of insulin resistance induced by JNK1 and possibly by IKK $\beta$ during obesity (Hirosumi et al., 2002; Sabio et al., 2010b). IKK $\beta$ haplo-insufficiency or JNK1invalidation could also reduce the pro-inflammatory effect of high-fat diet. In this regard, mice lacking IKK $\beta$ or JNK1 in immune cells were partially protected against obesity-induced inflammation (Arkan et al., 2005; Solinas et al., 2007; Vallerie et al., 2008). However, if the protection against systemic insulin resistance was obvious for IKK $\beta$ deletion (Arkan et al., 2005), contradictory results were reported for JNK1 invalidation (Solinas et al., 2007; Sabio et al., 2008; Vallerie et al., 2008).

The picture that emerges is that activation of these pathways in non-hematopoietic cells also participates in tissues inflammation and local or systemic insulin resistance. However, the consequences of IKK $\beta$ and JNK activation on the development of insulin resistance could totally differ and depend on the site of action, the level of expression and the impact on adiposity. Indeed, the activation of $\mathrm{IKK} \beta / \mathrm{NF}-\kappa \mathrm{B}$ in hepatocytes-induced liver inflammation and insulin resistance (Arkan et al., 2005; Cai et al., 2005; Tamura et al., 2007; Wunderlich et al., 2008) and was associated with a reduced ability of insulin to suppress neoglucogenesis (Arkan et al., 2005) and with an increased production of VLDL leading to the development of hypertriglyceridemia (van Diepen et al., 2011). At the opposite of these findings, the development of inflammation induced by a moderate IKK $\beta$ activation in adipose tissue and before the onset of obesity has been shown to be protective against diet-induced insulin resistance by limiting adipose tissue expansion and by increasing energy expenditure (Jiao et al., 2012). Furthermore, in contrast to the deleterious effect of IKK $\beta$, the activation of JNK pathway in liver

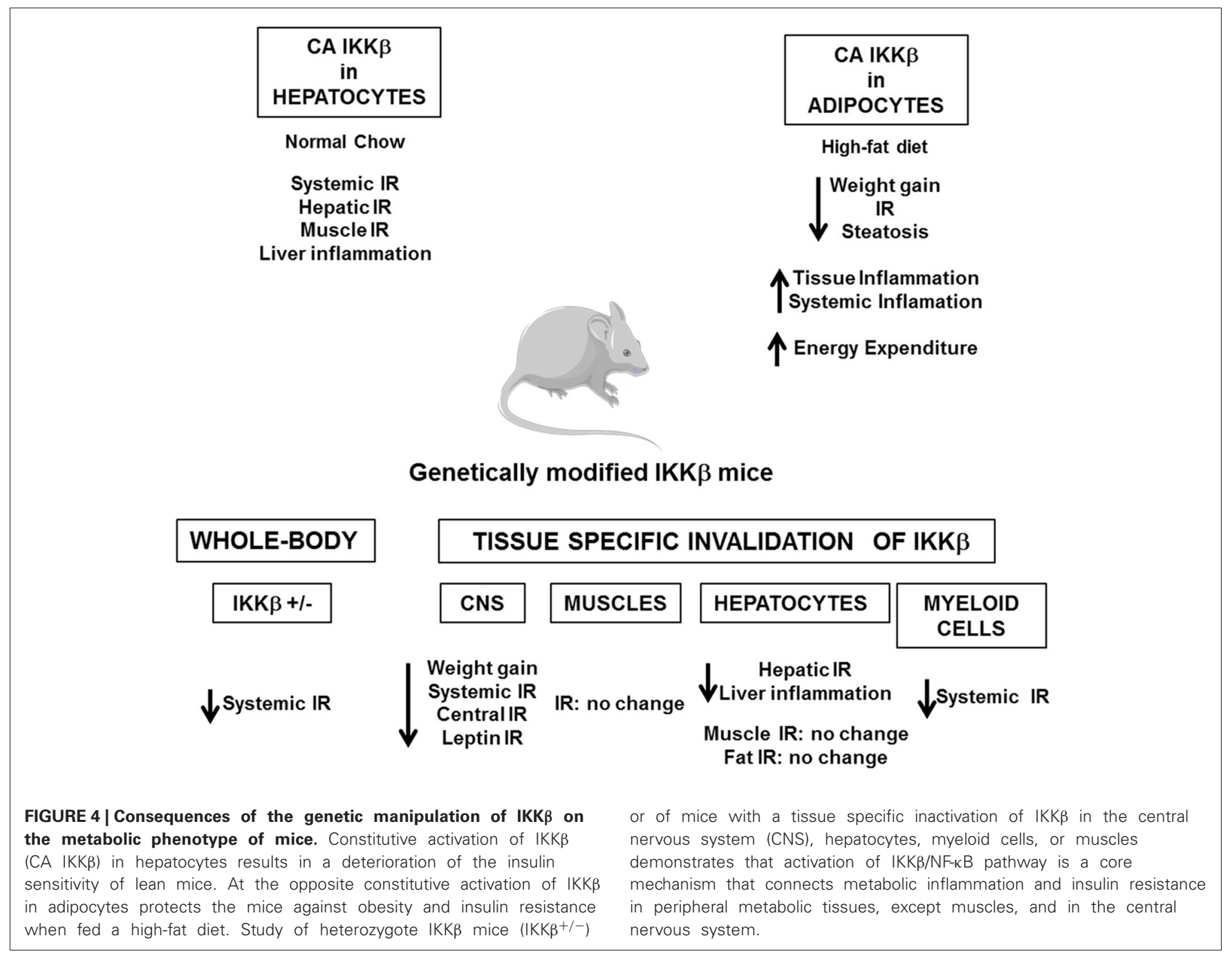




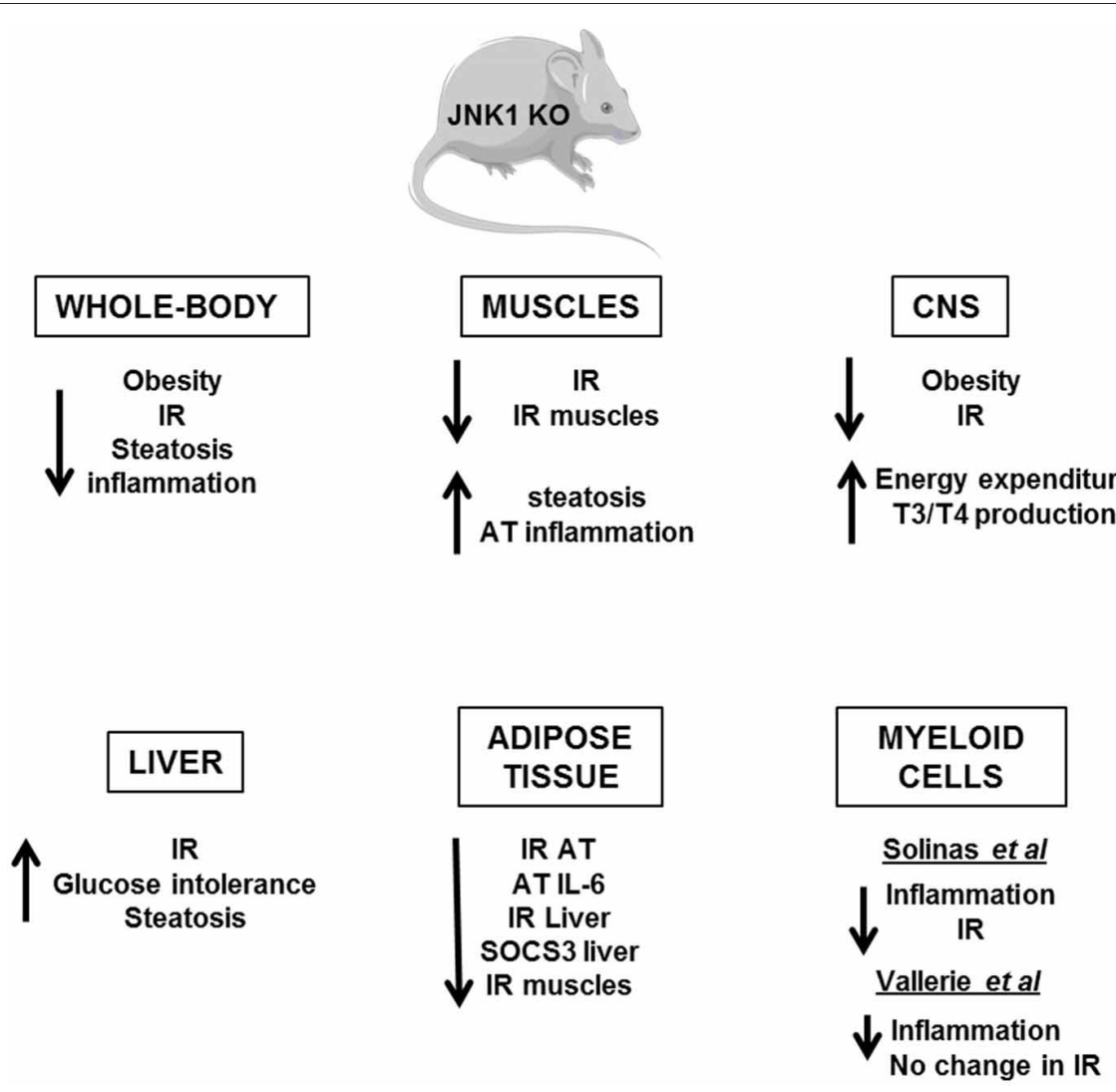

FIGURE 5 | Metabolic phenotype of whole-body JNK1 knockout mice and of conditional JNK1 knockout mice. Whole-body invalidation of JNK1 protects mice against diet-induced obesity and insulin resistance. Tissue-specific invalidation of JNK1 reveals that the lack of JNK1 in adipose tissue, muscles, or CNS protects against the development of obesity and/or insulin resistance. The lack of JNK1 in myeloid cells decreases obesity-induced inflammation but the impact on insulin resistance development is controversial. At the opposite, the lack of JNK1 in the hepatocytes alters liver function suggesting a protective role of JNK1. seems to have a protective role since hepatocyte-specific invalidation of JNK1 led to the development of glucose intolerance, insulin resistance, and liver steatosis even in lean mice (Sabio et al., 2009). This finding was quite unexpected given that the liver of obese whole-body JNK1-deficient mice was more insulin sensitive with less inflammation. Thus, it is possible that the inhibition of JNK1 in hepatocytes per se is detrimental whereas the combined inhibition of JNK1 in hepatocytes and in other liver cells of the liver has a protective effect. Further, organ to organ communication, especially cross-talk between liver and adipose tissue, could be another explanation since JNK1 invalidation in adipose tissue ameliorated liver insulin sensitivity (Sabio et al., 2008; Zhang et al., 2011). One important mediator of this crosstalk could be the adipocytokines, especially IL-6, which altered liver insulin sensitivity through induction of SOCS3 (Sabio and Davis, 2010). The consequences of JNK1 or IKK $\beta$ activation in muscles are also totally different. While inactivation of IKK $\beta$ in cultured muscle cells markedly reduced cytokine-induced insulin resistance (Austin et al., 2008), the study of mice with conditional knockout of IKK $\beta$ in muscles argues against a major role of muscular IKK $\beta$ activation in obesity-associated insulin resistance (Rohl et al., 2004). Muscle-specific invalidation of JNK1 improved high-fat diet-induced muscles insulin resistance but also led to an enhanced liver steatosis and to a mild increase in inflammatory mediator expression in adipose tissue. The crosstalk between these different organs was mediated by an increase in circulating triglycerides owing to a reduction in lipoprotein lipase expression in muscles (Sabio et al., 2010b). Systemic insulin sensitivity was slightly improved in those mice suggesting that the improved insulin sensitivity in muscles was sufficient to overcome the enhanced liver steatosis and adipose tissue inflammation. However, it is possible that with age, a worsening in insulin sensitivity develops.

Several evidences suggest that activation of IKK $\beta$ and JNK pathways in the hypothalamus by over-nutrition contributes to energy imbalance and weight gain in addition to their role in the development of insulin resistance. At the molecular level, ER stress that develops in hypothalamus owing to an oversupply in nutriments activates the IKK $\beta / N F-\kappa B$ pathway leading to local SOCS3 expression that interferes with both insulin and leptin signaling (Zhang et al., 2008). The mechanism by which JNK1 activation in the nervous system regulates body mass is different and complex. Two studies have revealed that invalidation of JNK1 in the nervous system markedly enhanced the 
production of thyroid hormones through the hypothalamicpituitary-thyroid axis leading to an increase in energy expenditure and a protection against obesity (Belgardt et al., 2010; Sabio et al., 2010a).

These studies support the idea that the over-activation of $\mathrm{IKK} \beta / \mathrm{NF}-\kappa \mathrm{B}$ and JNK pathways is a core mechanism that connects metabolic inflammation and insulin resistance both in peripheral tissues and in the CNS. This central role highlights IKK $\beta$ and JNK as potential pharmacological targets against the development of insulin resistance. In this regard, Shoelson and colleagues have shown that high-doses of salicylate and its derivative salsalate were able to inhibit IKK $\beta$ activity and to improve insulin sensitivity in obese mice (Donath and Shoelson, 2011). Importantly, recent proof of concept studies and clinical trials in type 2 diabetic patients suggest that salsalate ameliorates glucose tolerance through better insulin sensitivity, and/or via an increased insulin secretion (Koska et al., 2009; Goldfine et al., 2010). The consequences of the pharmacological targeting of JNK have been studied only in mice. Competitive inhibitors of ATP directed against JNK and specific small substrate-competitive inhibitors of JNK displayed protective effects against diet-induced insulin resistance and/or weight gain (Bogoyevitch and Arthur, 2008; Cho et al., 2008; Yang and Trevillyan, 2008). These results suggest that IKK $\beta$ or JNK inhibitors could be interesting therapeutic agents against insulin resistance and type 2 diabetes. However, it should be kept in mind that IKK $\beta / N F-\kappa B$ pathway is a central regulator of immunity and that JNK pathway regulates numerous physiologic processes. Chronic inhibition of these pathways might thus have side effects and favor the emergence of other pathologies.

\section{THE EXTRACELLULAR SIGNAL-REGULATED KINASES IN OBESITY DEVELOPMENT AND INSULIN RESISTANCE}

The Extracellular signal-Regulated Kinases (ERK) 1/2 (also known as p44 and p42 MAP kinase) are activated by several growth factors but also by inflammatory cytokines. The activation of ERK1/2 requires the phosphorylation of both tyrosine and threonine residues located in a TEY sequence. This phosphorylation is mediated by the MAP kinase kinase (MAP2K) MEK. The activation of MEK also requires its phosphorylation by MAP kinase kinase kinase (MAP3K). Depending on the stimuli, different MAP3Ks are engaged to phosphorylate MEK. The activated ERK1/2 phosphorylates numerous substrates with serine or threonine residues close to a proline residue (Keshet and Seger, 2010). The activity of ERK1/2 is increased in adipose tissue, liver, and muscles of obese/diabetic patients or mice for review see Tanti and Jager (2009). Several cellular studies have shown that activation of ERK1/2 by diabetogenic factors-induced IRS1 serine phosphorylation. These phosphorylation events decrease the interaction between IRS1 and the PI3K or inhibit the association between IRS1 and the insulin receptor and would thus diminish the metabolic effects of insulin (Tanti and Jager, 2009). This mechanism has relevant implications in human pathology since basal ERK activity and IRS1 phosphorylation are abnormally increased in primary muscle cells from type 2 diabetic patients (Bouzakri et al., 2003). In addition, activation of the ERK pathway by the inflammatory cytokines, especially IL- $1 \beta$, in adipocytes also induced a decrease in the transcription of IRS1 mRNA, leading to a decrease in insulin signaling and glucose transport (Jager et al., 2007). ERK activation by inflammatory cytokines could also indirectly promote insulin resistance by the stimulation of adipocyte lipolysis and the release of free fatty acids (Souza et al., 2003).

The contribution of ERK pathway in the development of obesity and insulin resistance was first demonstrated by our study of ERK1-deficient mice (Bost et al., 2005). Those mice were protected against obesity when fed a high-fat diet, because of a decrease in adipogenesis and an increase in postprandial energy expenditure. The lack of obesity was associated with a better glucose and insulin tolerance compared to wild-type mice (Bost et al., 2005). Conversely, over-activation of the ERK pathway owing to deletion of the signaling adapter p62 resulted in the development of mature-onset obesity and insulin resistance with reduced energy expenditure and increased adipogenesis (Rodriguez et al., 2006). This phenotype was probably due to the over-activation of ERK1 rather than ERK2 since deletion of ERK1 in the $\mathrm{p} 62^{-/-}$genetic background reversed the phenotype (Lee et al., 2010). Those studies clearly highlighted the role of ERK1 in the development of obesity but did not allow concluding whether ERK1 could modulate the insulin sensitivity independently of its effect on body weight. However, we have recently shown that invalidation of ERK1 protected obese $o b / o b$ mice against insulin resistance and adipose tissue inflammation without any changes in obesity (Jager et al., 2011). Another study also suggested that inhibition of ERK had beneficial effects on insulin resistance independently of an effect on body weight gain (Emanuelli et al., 2008a).

The pharmacological targeting of ERK1/2 against insulin resistance could have a series of drawbacks since they are involved in numerous biological processes. A possible alternative choice would be to target proteins which control ERK activity, specifically in response to inflammatory stresses which develop during obesity. In this regard, interesting candidates could be specific MAP3 kinases that are important in innate immune receptor signaling to MAP kinase activation (Symons et al., 2006).

Among the different MAP3K that control ERK activity, our team recently identified the kinase Tpl2 (Tumor progression locus, MAP3K8) as a potential new player in adipose tissue dysfunction and inflammation (Jager et al., 2010). In immune cells, Tpl2 plays an important role in the production of inflammatory cytokines, especially TNF $\alpha$ (Dumitru et al., 2000), and it is also involved in cytokines signaling downstream of innate immunoreceptors (Gantke et al., 2011). The importance of Tpl2 in inflammation has been demonstrated by the resistance to endotoxin shock and the lack of TNF- $\alpha$ production by macrophages of the Tpl2-deficient mice (Dumitru et al., 2000). Further, Tpl2 is a critical regulator of pancreatic, lung, and bowel inflammation in mice (Gantke et al., 2011). In non-stimulated cells, Tpl2 binds in its inactive form to $\mathrm{p} 105 \mathrm{NF}-\kappa \mathrm{B}$ and is activated by different inflammatory stimuli through phosphorylation and degradation

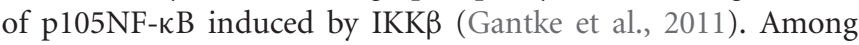
them, LPS, TNF- $\alpha$, IL- $1 \beta$, and CD40 are involved in obesityinduced inflammation and insulin resistance (Poggi et al., 2009; Tanti and Jager, 2009) suggesting a potential role for Tpl2 in this 
pathology. Recently, we found Tpl2 up-regulated in adipose tissue of obese mice and patients. Tpl2 was involved in the lipolytic effect the inflammatory cytokines and in the serine phosphorylation of IRS1 in adipocytes (Jager et al., 2010). Based on these findings, one can hypothesize that the targeting of Tpl 2 could have beneficial effects in the context of obesity by reducing the production of inflammatory cytokines by adipose tissue immune cells and by blocking their deleterious effects in adipocytes. In agreement, one recent study has shown that $\mathrm{Tpl} 2$ inactivation protected the mice against insulin resistance with a reduction in liver and adipose tissue inflammation (Perfield et al., 2011). However, another study failed to confirm this finding (Lancaster et al., 2012). Thus, further studies are needed to conclude whether the targeting of $\mathrm{Tpl} 2$ could improve the complications of obesity.

\section{CONCLUSION}

The discovery that metabolic diseases are associated with a lowgrade inflammatory state has opened a new area of research to understand how inflammation develops and how it impact on metabolic pathways. It appears that a cross-talk between immune cells and metabolic cells plays a central role in the disturbance of metabolic homeostasis. High levels of dietary saturated fatty acids or of their metabolites can be detected by immune sensors such as TLR or inflammasome leading to the synthesis of inflammatory cytokines in different metabolic tissues. Dietary fat

\section{REFERENCES}

Amar, J., Chabo, C., Waget, A., Klopp, P., Vachoux, C., BermudezHumaran, L. G., et al. (2011). Intestinal mucosal adherence and translocation of commensal bacteria at the early onset of type 2 diabetes: molecular mechanisms and probiotic treatment. $E M B O$ Mol. Med. 3, 559-572.

Arkan, M. C., Hevener, A. L., Greten, F. R., Maeda, S., Li, Z. W., Long, J. M., et al. (2005). IKK-beta links inflammation to obesity-induced insulin resistance. Nat. Med. 11, 191-198.

Austin, R. L., Rune, A., Bouzakri, K., Zierath, J. R., and Krook, A. (2008). siRNA-mediated reduction of inhibitor of nuclear factor-kappaB kinase prevents tumor necrosis factor-alpha-induced insulin resistance in human skeletal muscle. Diabetes 57, 2066-2073.

Banks, A., Li, J., McKeag, L., Hribal, M., Kashiwada, M., Accili, D., et al. (2005). Deletion of SOCS7 leads to enhanced insulin action and enlarged islets of Langerhans. J. Clin. Invest. 115, 2462-2471.

Belgardt, B. F., Mauer, J., Wunderlich, F. T., Ernst, M. B., Pal, M., Spohn, G., et al. (2010). Hypothalamic and pituitary c-Jun $\mathrm{N}$-terminal kinase 1 signaling coordinately regulates glucose metabolism. Proc. Natl. Acad. Sci. U.S.A. 107, 6028-6033.
Benomar, Y., Berthou, F., Vacher, C. M., Bailleux, V., Gertler, A., Djiane, J., et al. (2009). Leptin but not ciliary neurotrophic factor (CNTF) induces phosphotyrosine phosphatase-1B expression in human neuronal cells (SH-SY5Y): putative explanation of CNTF efficacy in leptin-resistant state. Endocrinology 150, 1182-1191.

Bertola, A., Ciucci, T., Rousseau, D., Bourlier, V., Duffaut, C., Bonnafous, S., et al. (2012). Identification of adipose tissue dendritic cells correlated with obesity-associated insulin-resistance and inducing Th17 responses in mice and patients. Diabetes 61, 2238-2247.

Bogoyevitch, M. A., and Arthur, P. G. (2008). Inhibitors of c-Jun Nterminal kinases: JuNK no more? Biochim. Biophys. Acta 1784, 76-93.

Bost, F., Aouadi, M., Caron, L., Even, P., Belmonte, N., Prot, M., et al. (2005). The extracellular signal-regulated kinase isoform ERK1 is specifically required for in vitro and in vivo adipogenesis. Diabetes 54, 402-411.

Boura-Halfon, S., and Zick, Y. (2009). Phosphorylation of IRS proteins, insulin action, and insulin resistance. Am. J. Physiol. Endocrinol. Metab. 296, E581-E591.

Bouzakri, K., Roques, M., Gual, P., Espinosa, S., Guebre-Egziabher, F., Riou, J. P., et al. (2003). Reduced

can also modify the intestinal microbiota that produces different inflammatory molecules leading to an inappropriate immune reaction. The inflammatory cytokines, saturated fatty acids, and LPS activate a network of signaling pathways that impinges on insulin signaling leading to alterations in metabolic cell functions. Hence, the importance of immune sensors and of different kinases suggests that new strategies targeting these proteins could be conceived to improve the metabolic complications of obesity.

\section{ACKNOWLEDGMENTS}

We thank Drs. Mireille Cormont and Yannick Le MarchandBrustel for helpful suggestions and critical reading of the manuscript. We would like to apologize to colleagues for works which were not cited due to space limitation.

Author's work was supported by INSERM and CNRS and the University of Nice- Sophia Antipolis (France). Jean-François Tanti acknowledges support from ALFEDIAM-Abbott Laboratory, the French National Research Agency (grant ANR-2010-BLAN1117-01) and the European Commission (Brussels, Belgium) (Contract LSHM-CT-2005-018734, Hepatic and Adipose Tissue and Functions in the Metabolic Syndrome, HEPADIP). Franck Ceppo is supported by a fellowship from the Region Provence Alpes-Cote d'Azur. Flavien Berthou is supported by the ANR grant ANR-2010-BLAN-1117-01.

activation of phosphatidylinositol3 kinase and increased serine 636 phosphorylation of insulin receptor substrate- 1 in primary culture of skeletal muscle cells from patients with type 2 diabetes. Diabetes 52, 1319-1325.

Burcelin, R., Serino, M., Chabo, C., Blasco-Baque, V., and Amar, J. (2011). Gut microbiota and diabetes: from pathogenesis to therapeutic perspective. Acta Diabetol. 48, 257-273.

Cai, D., Yuan, M., Frantz, D. F., Melendez, P. A., Hansen, L., Lee, J., et al. (2005). Local and systemic insulin resistance resulting from hepatic activation of IKKbeta and NF-kappaB. Nat. Med. 11, 183-190.

Cani, P. D., and Delzenne, N. M. (2009). The role of the gut microbiota in energy metabolism and metabolic disease. Curr. Pharm. Des. 15, 1546-1558.

Caricilli, A., Picardi, P., de Abreu, L. L., Ueno, M., Prada, P., Ropelle, E., et al. (2011). Gut microbiota is a key modulator of insulin resistance in TLR 2 knockout mice. PLoS Biol. 9:e1001212. doi: 10.1371/journal.pbio. 1001212

Caricilli, A. M., Nascimento, P. H., Pauli, J. R., Tsukumo, D. M., Velloso, L. A., Carvalheira, J. B., et al. (2008). Inhibition of toll-like receptor 2 expression improves insulin sensitivity and signaling in muscle and white adipose tissue of mice fed a high-fat diet. J. Endocrinol. 199, 399-406.

Cho, H., Black, S. C., Looper, D., Shi, M., Kelly-Sullivan, D., Timofeevski, S., et al. (2008). Pharmacological characterization of a small molecule inhibitor of c-Jun kinase. Am. J. Physiol. Endocrinol. Metab. 295, E1142-E1151.

Cnop, M., Foufelle, F., and Velloso, L. A. (2011). Endoplasmic reticulum stress, obesity and diabetes. Trends Mol. Med. 18, 59-68.

Coenen, K., Gruen, M., Lee-Young, R., Puglisi, M., Wasserman, D., and Hasty, A. (2009). Impact of macrophage toll-like receptor 4 deficiency on macrophage infiltration into adipose tissue and the artery wall in mice. Diabetologia 52, 318-328.

Copps, K. D., and White, M. F. (2012). Regulation of insulin sensitivity by serine/threonine phosphorylation of insulin receptor substrate proteins IRS1 and IRS2. Diabetologia 55, 2565-2582.

Davis, J. E., Gabler, N. K., WalkerDaniels, J., and Spurlock, M. E. (2008). Tlr-4 deficiency selectively protects against obesity induced by diets high in saturated fat. Obesity (Silver Spring) 16, 1248-1255. 
Ding, Y., Subramanian, S., Montes, V., Goodspeed, L., Wang, S., Han, C., et al. (2012). Toll-like receptor 4 deficiency decreases atherosclerosis but does not protect against inflammation in obese low-density lipoprotein receptor-deficient mice. Arterioscler. Thromb. Vasc. Biol. 32, 1596-1604.

Donath, M. Y., and Shoelson, S. E. (2011). Type 2 diabetes as an inflammatory disease. Nat. Rev. Immunol. 11, 98-107.

Dumitru, C. D., Ceci, J. D., Tsatsanis, C., Kontoyiannis, D., Stamatakis, K., Lin, J. H., et al. (2000). TNFalpha induction by LPS is regulated posttranscriptionally via a Tpl2/ERK-dependent pathway. Cell 103, 1071-1083.

Ehses, J., Meier, D., Wueest, S., Rytka, J., Boller, S., Wielinga, P., et al. (2010). Toll-like receptor 2-deficient mice are protected from insulin resistance and beta cell dysfunction induced by a high-fat diet. Diabetologia 53, 1795-1806.

Emanuelli, B., Eberle, D., Suzuki, R., and Kahn, C. R. (2008a). Overexpression of the dualspecificity phosphatase MKP-4/DUSP-9 protects against stress-induced insulin resistance. Proc. Natl. Acad. Sci. U.S.A. 105, 3545-3550.

Emanuelli, B., Macotela, Y., Boucher, J., and Ronald Kahn, C. (2008b). SOCS-1 deficiency does not prevent diet-induced insulin resistance. Biochem. Biophys. Res. Commun. 377, 447-452.

Emanuelli, B., Peraldi, P., Filloux, C., Sawka-Verhelle, D., Hilton, D., and Van Obberghen, E. (2000). SOCS-3 is an insulin-induced negative regulator of insulin signaling. J. Biol. Chem. 275, 15985-15991.

Erridge, C., and Samani, N. J. (2009). Saturated fatty acids do not directly stimulate Toll-like receptor signaling. Arterioscler. Thromb. Vasc. Biol. 29, 1944-1949.

Fischer, H., Ellstrom, P., Ekstrom, K., Gustafsson, L., Gustafsson, M., and Svanborg, C. (2007). Ceramide as a TLR4 agonist; a putative signalling intermediate between sphingolipid receptors for microbial ligands and TLR4. Cell. Microbiol. 9, 1239-1251.

Flamment, M., Hajduch, E., Ferre, P., and Foufelle, F. (2012). New insights into ER stress-induced insulin resistance. Trends Endocrinol. Metab. 23, 381-390.

Fresno, M., Alvarez, R., and Cuesta, N. (2011). Toll-like receptors, inflammation, metabolism and obesity. Arch. Physiol. Biochem. 117, 151-164.
Gantke, T., Sriskantharajah, S., and Ley, S. C. (2011). Regulation and function of TPL-2, an IkB kinaseregulated MAP kinase kinase kinase. Cell Res. 21, 131-145.

Goldfine, A. B., Fonseca, V., Jablonski, K. A., Pyle, L., Staten, M. A., and Shoelson, S. E. (2010). The effects of salsalate on glycemic control in patients with type 2 diabetes: a randomized trial. Ann. Intern. Med. 152, 346-357.

Gregor, M. F., and Hotamisligil, G. S. (2011). Inflammatory mechanisms in obesity. Annu. Rev. Immunol. 29, 415-445.

Gual, P., Le Marchand-Brustel, Y., and Tanti, J. F. (2005). Positive and negative regulation of insulin signaling through IRS-1 phosphorylation. Biochimie 87, 99-109.

Gurcel, L., Abrami, L., Girardin, S. Tschopp, J., and van der Goot, F. G. (2006). Caspase-1 activation of lipid metabolic pathways in response to bacterial pore-forming toxins promotes cell survival. Cell 126, 1135-1145.

Himes, R., and Smith, C. (2010). Tlr2 is critical for diet-induced metabolic syndrome in a murine model. FASEB J. 24, 731-739.

Hirosumi, J., Tuncman, G., Chang, L., Gorgun, C. Z., Uysal, K. T., Maeda, K., et al. (2002). A central role for JNK in obesity and insulin resistance. Nature 420, 333-336.

Howard, J. K., Cave, B. J., Oksanen, L. J., Tzameli, I., Bjorbaek, C., and Flier, J. S. (2004). Enhanced leptin sensitivity and attenuation of dietinduced obesity in mice with haploinsufficiency of Socs3. Nat. Med. 10, 734-738.

Im, S. S., Yousef, L., Blaschitz, C., Liu, J. Z., Edwards, R. A., Young, S. G., et al. (2011). Linking lipid metabolism to the innate immune response in macrophages through sterol regulatory element binding protein-1a. Cell Metab. 13, 540-549.

Jager, J., Corcelle, V., Gremeaux, T., Laurent, K., Waget, A., Pages, G., et al. (2011). Deficiency in the extracellular signal-regulated kinase 1 (ERK1) protects leptin-deficient mice from insulin resistance without affecting obesity. Diabetologia 54, 180-189.

Jager, J., Gremeaux, T., Cormont, M., Le Marchand-Brustel, Y., and Tanti, J. F. (2007). Interleukin-1beta-induced insulin resistance in adipocytes through down-regulation of insulin receptor substrate-1 expression. Endocrinology 148, 241-251.

Jager, J., Gremeaux, T., Gonzalez, T., Bonnafous, S., Debard, C.,
Laville, M., et al. (2010). The Tpl2 kinase is up-regulated in adipose tissue in obesity and may mediate IL-1(Minamino et al.) and TNF(alpha) effects on ERK activation and lipolysis. Diabetes 59, 61-70.

Jamieson, E., Chong, M., Steinberg, G., Jovanovska, V., Fam, B., Bullen, D., et al. (2005). Socs1 deficiency enhances hepatic insulin signaling. J. Biol. Chem. 280, 31516-31521.

Jiao, P., Feng, B., Ma, J., Nie, Y., Paul, E., Li, Y., et al. (2012). Constitutive activation of IKKbeta in adipose tissue prevents diet-induced obesity in mice. Endocrinology 153, 154-165.

Jorgensen, S., O’Neill, H., Sylow, L. Honeyman, J., Hewitt, K., Palanivel, R., et al. (2012). Deletion of skeletal muscle SOCS3 prevents insulin resistance in obesity. Diabetes 62 56-64.

Kaddai, V., Jager, J., Gonzalez, T., Najem-Lendom, R., Bonnafous, S., Tran, A., et al. (2009). Involvement of TNF-alpha in abnormal adipocyte and muscle sortilin expression in obese mice and humans. Diabetologia 52, 932-940.

Keshet, Y., and Seger, R. (2010). The MAP kinase signaling cascades: a system of hundreds of components regulates a diverse array of physiological functions. Methods Mol. Biol. 661, 3-38.

Kievit, P., Howard, J., Badman, M., Balthasar, N., Coppari, R., Mori, H., et al. (2006). Enhanced leptin sensitivity and improved glucose homeostasis in mice lacking suppressor of cytokine signaling-3 in POMC-expressing cells. Cell Metab. 4, 123-132.

Kim, F., Pham, M., Luttrell, I., Bannerman, D. D., Tupper, J., Thaler, J., et al. (2007). Toll-like receptor-4 mediates vascular inflammation and insulin resistance in diet-induced obesity. Circ. Res. 100, 1589-1596.

Kleinridders, A., Schenten, D., Könner, A., Belgardt, B., Mauer, J., Okamura T., et al. (2009). MyD88 signaling in the CNS is required for development of fatty acid-induced leptin resistance and diet-induced obesity. Cell Metab. 10, 249-259.

Koenen, T. B., Stienstra, R., van Tits L. J., Joosten, L. A., van Velzen, J. F., Hijmans, A., et al. (2011). The inflammasome and caspase- 1 activation: a new mechanism underlying increased inflammatory activity in human visceral adipose tissue. Endocrinology 152, 3769-3778.

Könner, A., and Brüning, J. (2011). Toll-like receptors: linking inflammation to metabolism. Trends Endocrinol. Metab. 22, 16-23.
Koska, J., Ortega, E., Bunt, J. C., Gasser, A., Impson, J., Hanson, R. L., et al. (2009). The effect of salsalate on insulin action and glucose tolerance in obese non-diabetic patients: results of a randomised doubleblind placebo-controlled study. Diabetologia 52, 385-393.

Kuo, L. H., Tsai, P. J., Jiang, M. J., Chuang, Y. L., Yu, L., Lai, K. T. A., et al. (2011). Toll-like receptor 2 deficiency improves insulin sensitivity and hepatic insulin signalling in the mouse. Diabetologia 54, 168-179.

Lagathu, C., Yvan-Charvet, L., Bastard, J. P., Maachi, M., QuignardBoulange, A., Capeau, J., et al. (2006). Long-term treatment with interleukin-1beta induces insulin resistance in murine and human adipocytes. Diabetologia 49, 2162-2173.

Lancaster, G. I., Kowalski, G. M., Estevez, E., Kraakman, M. J., Grigoriadis, G., Febbraio, M. A., et al. (2012). Tumor progression locus 2 (Tpl2) deficiency does not protect against obesity-induced metabolic disease. PLOS ONE 7:e39100. doi: 10.1371/journal.pone.0039100

Larsen, C. M., Faulenbach, M., Vaag, A., Volund, A., Ehses, J. A., Seifert, B., et al. (2007). Interleukin-1receptor antagonist in type 2 diabetes mellitus. N. Engl. J. Med. 356, 1517-1526.

Lebrun, P., Cognard, E., Bellon-Paul, R., Gontard, P., Filloux, C., JehlPietri, C., et al. (2009). Constitutive expression of suppressor of cytokine signalling-3 in skeletal muscle leads to reduced mobility and overweight in mice. Diabetologia 52, 2201-2212.

Lebrun, P., and Van Obberghen, E. (2008). SOCS proteins causing trouble in insulin action. Acta Physiol. (Oxf.) 192, 29-36.

Lee, D. F., Kuo, H. P., Chen, C. T., Wei, Y., Chou, C. K., Hung, J. Y., et al. (2008). IKKbeta suppression of TSC1 function links the mTOR pathway with insulin resistance. Int J. Mol. Med. 22, 633-638.

Lee, S. J., Pfluger, P. T., Kim, J. Y., Nogueiras, R., Duran, A., Pages, G., et al. (2010). A functional role for the p62-ERK1 axis in the control of energy homeostasis and adipogenesis. EMBO Rep. 11, 226-232.

Li, L., Chen, L., Hu, L., Liu, Y., Sun, H.-Y., Tang, J., et al. (2011). Nuclear factor high-mobility group boxl mediating the activation of Toll-like receptor 4 signaling in hepatocytes in the early stage of 
nonalcoholic fatty liver disease in mice. Hepatology 54, 1620-1630.

Li, L., Grønning, L., Anderson, P., Li, S., Edvardsen, K., Johnston, J., et al. (2004). Insulin induces SOCS-6 expression and its binding to the p85 monomer of phosphoinositide 3-kinase, resulting in improvement in glucose metabolism. J. Biol. Chem. 279, 34107-34114.

Lolmede, K., Duffaut, C., ZakaroffGirard, A., and Bouloumie, A. (2011). Immune cells in adipose tissue: key players in metabolic disorders. Diabetes Metab. 37, 283-290.

Milanski, M., Degasperi, G., Coope, A., Morari, J., Denis, R., Cintra, D., et al. (2009). Saturated fatty acids produce an inflammatory response predominantly through the activation of TLR4 signaling in hypothalamus: implications for the pathogenesis of obesity. J. Neurosci. 29, 359-370.

Mogensen, T. H. (2009). Pathogen recognition and inflammatory signaling in innate immune defenses. Clin. Microbiol. Rev. 22, 240-273.

Mori, H., Hanada, R., Hanada, T., Aki, D., Mashima, R., Nishinakamura, H., et al. (2004). Socs3 deficiency in the brain elevates leptin sensitivity and confers resistance to diet-induced obesity. Nat. Med. 10, 739-743.

Nakamura, T., Furuhashi, M., Li, P., Cao, H., Tuncman, G., Sonenberg, N., et al. (2010). Double-stranded RNA-dependent protein kinase links pathogen sensing with stress and metabolic homeostasis. Cell 140, 338-348.

Nicholson, J. K., Holmes, E., Kinross, J., Burcelin, R., Gibson, G., Jia, W., et al. (2012). Host-gut microbiota metabolic interactions. Science 336, 1262-1267.

Orr, J., Puglisi, M., Ellacott, K., Lumeng, C., Wasserman, D., and Hasty, A. (2012). Toll-like receptor 4 deficiency promotes the alternative activation of adipose tissue macrophages. Diabetes 61, 2718-2727.

Oslowski, C. M., Hara, T., O'SullivanMurphy, B., Kanekura, K., Lu, S., Hara, M., et al. (2012). Thioredoxin-interacting protein mediates ER stress-induced beta cell death through initiation of the inflammasome. Cell Metab. 16, 265-273.

Ozcan, U., Cao, Q., Yilmaz, E., Lee, A. H., Iwakoshi, N. N., Ozdelen, E., et al. (2004). Endoplasmic reticulum stress links obesity, insulin action, and type 2 diabetes. Science 306, 457-461.
Ozcan, U., Ozcan, L., Yilmaz, E., Duvel, K., Sahin, M., Manning, B. D., et al. (2008). Loss of the tuberous sclerosis complex tumor suppressors triggers the unfolded protein response to regulate insulin signaling and apoptosis. Mol. Cell 29, 541-551.

Pal, D., Dasgupta, S., Kundu, R., Maitra, S., Das, G., Mukhopadhyay, S., et al. (2012). Fetuin-A acts as an endogenous ligand of TLR4 to promote lipid-induced insulin resistance. Nat. Med. 18, 1279-1285.

Palanivel, R., Fullerton, M., Galic, S., Honeyman, J., Hewitt, K., Jorgensen, S., et al. (2012). Reduced Socs 3 expression in adipose tissue protects female mice against obesity-induced insulin resistance. Diabetologia 55, 3083-3093.

Perfield, J. W. 2nd., Lee, Y., Shulman, G. I., Samuel, V. T., Jurczak, M. J., Chang, E., et al. (2011). Tumor progression locus 2 (TPL2) regulates obesity-associated inflammation and insulin resistance. Diabetes 60, 1168-1176.

Poggi, M., Bastelica, D., Gual, P., Iglesias, M., Gremeaux, T., Knauf, C., et al. (2007). C3H/HeJ mice carrying a toll-like receptor 4 mutation are protected against the development of insulin resistance in white adipose tissue in response to a high-fat diet. Diabetologia 50, 1267-1276.

Poggi, M., Jager, J., Paulmyer-Lacroix, O., Peiretti, F., Gremeaux, T., Verdier, M., et al. (2009). The inflammatory receptor CD40 is expressed on human adipocytes: contribution to crosstalk between lymphocytes and adipocytes. Diabetologia 52, 1152-1163.

Radin, M., Sinha, S., Bhatt, B., Dedousis, N., and O'Doherty, R. (2008). Inhibition or deletion of the lipopolysaccharide receptor Toll-like receptor- 4 confers partial protection against lipid-induced insulin resistance in rodent skeletal muscle. Diabetologia 51, 336-346.

Regazzetti, C., Peraldi, P., Gremeaux, T., Najem-Lendom, R., Ben-Sahra, I., Cormont, M., et al. (2009). Hypoxia decreases insulin signaling pathways in adipocytes. Diabetes 58 , 95-103.

Rieusset, J., Bouzakri, K., Chevillotte, E., Ricard, N., Jacquet, D., Bastard, J. P., et al. (2004). Suppressor of cytokine signaling 3 expression and insulin resistance in skeletal muscle of obese and type 2 diabetic patients. Diabetes 53, 2232-2241.

Rodriguez, A., Duran, A., Selloum, M., Champy, M.-F., Diez-Guerra, F. J., Flores, J. M., et al. (2006). Matureonset obesity and insulin resistance in mice deficient in the signaling adapter p62. Cell Metab. 3, 211-222.

Rohl, M., Pasparakis, M., Baudler, S., Baumgartl, J., Gautam, D., Huth, M., et al. (2004). Conditional disruption of IkappaB kinase 2 fails to prevent obesity-induced insulin resistance. J. Clin. Invest. 113, 474-481.

Saberi, M., Woods, N. B., de Luca, C., Schenk, S., Lu, J. C., Bandyopadhyay, G., et al. (2009). Hematopoietic cell-specific deletion of toll-like receptor 4 ameliorates hepatic and adipose tissue insulin resistance in high-fat-fed mice. Cell Metab. 10, 419-429.

Sabio, G., Cavanagh-Kyros, J., Barrett, T., Jung, D. Y., Ko, H. J., Ong, H., et al. (2010a). Role of the hypothalamic-pituitary-thyroid axis in metabolic regulation by JNK1. Genes Dev. 24, 256-264.

Sabio, G., Kennedy, N. J., CavanaghKyros, J., Jung, D. Y., Ko, H. J., Ong, H., et al. (2010b). Role of muscle c-Jun NH2-terminal kinase 1 in obesity-induced insulin resistance. Mol. Cell. Biol. 30, 106-115.

Sabio, G., Cavanagh-Kyros, J., Ko, H. J., Jung, D. Y., Gray, S., Jun, J. Y., et al. (2009). Prevention of steatosis by hepatic JNK1. Cell Metab. 10, 491-498.

Sabio, G., Das, M., Mora, A., Zhang, Z., Jun, J. Y., Ko, H. J., et al. (2008). A stress signaling pathway in adipose tissue regulates hepatic insulin resistance. Science 322, 1539-1543.

Sabio, G., and Davis, R. J. (2010). cJun NH2-terminal kinase 1 (JNK1): roles in metabolic regulation of insulin resistance. Trends Biochem. Sci. 35, 490-496.

Sachithanandan, N., Fam, B., Fynch, S., Dzamko, N., Watt, M., Wormald, S., et al. (2010). Liver-specific suppressor of cytokine signaling-3 deletion in mice enhances hepatic insulin sensitivity and lipogenesis resulting in fatty liver and obesity. Hepatology $52,1632-1642$.

Sachithanandan, N., Graham, K., Galic, S., Honeyman, J., Fynch, S., Hewitt, K., et al. (2011). Macrophage deletion of SOCS1 increases sensitivity to LPS and palmitic acid and results in systemic inflammation and hepatic insulin resistance. Diabetes 60, 2023-2031.

Schertzer, J. D., Tamrakar, A. K., Magalhaes, J. G., Pereira, S., Bilan, P. J., Fullerton, M. D., et al. (2011). NOD1 activators link innate immunity to insulin resistance. Diabetes 60, 2206-2215.

Shi, H., Cave, B., Inouye, K., Bjorbaek, C., and Flier, J. S. (2006a). Overexpression of suppressor of cytokine signaling 3 in adipose tissue causes local but not systemic insulin resistance. Diabetes 55, 699-707.

Shi, H., Kokoeva, M., Inouye, K., Tzameli, I., Yin, H., and Flier, J. (2006b). TLR4 links innate immunity and fatty acid-induced insulin resistance. J. Clin. Invest. 116, 3015-3025.

Solinas, G., and Karin, M. (2010). JNK1 and IKKbeta: molecular links between obesity and metabolic dysfunction. FASEB J. 24, 2596-2611.

Solinas, G., Vilcu, C., Neels, J. G., Bandyopadhyay, G. K., Luo, J. L., Naugler, W., et al. (2007). JNK1 in hematopoietically derived cells contributes to diet-induced inflammation and insulin resistance without affecting obesity. Cell Metab. 6, 386-397.

Souza, S. C., Palmer, H. J., Kang, Y. H., Yamamoto, M. T., Muliro, K. V., Paulson, K. E., et al. (2003). TNFalpha induction of lipolysis is mediated through activation of the extracellular signal related kinase pathway in 3T3-L1 adipocytes. J. Cell. Biochem. 89, 1077-1086.

Stienstra, R., Joosten, L. A., Koenen, T., van Tits, B., van Diepen, J. A., van den Berg, S. A., et al. (2010). The inflammasome-mediated caspase-1 activation controls adipocyte differentiation and insulin sensitivity. Cell Metab. 12, 593-605.

Stienstra, R., van Diepen, J. A., Tack, C. J., Zaki, M. H., van de Veerdonk, F. L., Perera, D., et al. (2011). Inflammasome is a central player in the induction of obesity and insulin resistance. Proc. Natl. Acad. Sci. U.S.A. 108, 15324-15329.

Suganami, T., Mieda, T., Itoh, M., Shimoda, Y., Kamei, Y., and Ogawa, Y. (2007a). Attenuation of obesityinduced adipose tissue inflammation in $\mathrm{C} 3 \mathrm{H} / \mathrm{HeJ}$ mice carrying a Toll-like receptor 4 mutation. Biochem. Biophys. Res. Commun. 354, 45-49.

Suganami, T., Tanimoto-Koyama, K., Nishida, J., Itoh, M., Yuan, X., Mizuarai, S., et al. (2007b). Role of the Toll-like receptor 4/NF-kappaB pathway in saturated fatty acidinduced inflammatory changes in the interaction between adipocytes and macrophages. Arterioscler. Thromb. Vasc. Biol. 27, 84-91.

Sun, S., Ji, Y., Kersten, S., and Qi, L. (2012). Mechanisms of inflammatory responses in obese adipose tissue. Annu. Rev. Nutr. 32, 261-286.

Symons, A., Beinke, S., and Ley, S. C. (2006). MAP kinase kinase kinases and innate immunity. Trends Immunol. 27, 40-48. 
Tamrakar, A. K., Schertzer, J. D., Chiu, T. T., Foley, K. P., Bilan, P. J., Philpott, D. J., et al. (2010). NOD2 activation induces muscle cell-autonomous innate immune responses and insulin resistance. Endocrinology 151, 5624-5637.

Tamura, Y., Ogihara, T., Uchida, T., Ikeda, F., Kumashiro, N., Nomiyama, T., et al. (2007). Amelioration of glucose tolerance by hepatic inhibition of nuclear factor kappaB in $\mathrm{db} / \mathrm{db}$ mice. Diabetologia 50, 131-141.

Taniguchi, C. M., Emanuelli, B., and Kahn, C. R. (2006). Critical nodes in signalling pathways: insights into insulin action. Nat. Rev. Mol. Cell Biol. 7, 85-96.

Tanti, J. F., Gremeaux, T., van Obberghen, E., and Le MarchandBrustel, Y. (1994). Serine/threonine phosphorylation of insulin receptor substrate 1 modulates insulin receptor signaling. J. Biol. Chem. 269, 6051-6057.

Tanti, J. F., and Jager, J. (2009). Cellular mechanisms of insulin resistance: role of stress-regulated serine kinases and insulin receptor substrates (IRS) serine phosphorylation. Curr. Opin. Pharmacol. 9, 753-762.

Torisu, T., Sato, N., Yoshiga, D., Kobayashi, T., Yoshioka, T., Mori, H., et al. (2007). The dual function of hepatic SOCS3 in insulin resistance in vivo. Genes Cells 12, 143-154.

Triantafilou, M., Gamper, F. G., Haston, R. M., Mouratis, M. A., Morath, S., Hartung, T., et al. (2006). Membrane sorting of toll-like receptor (TLR)-2/6 and TLR2/1 heterodimers at the cell surface determines heterotypic associations with CD36 and intracellular targeting. J. Biol. Chem. 281, 31002-31011.

Tschopp, J., and Schroder, K. (2010). NLRP3 inflammasome activation: the convergence of multiple signalling pathways on ROS production? Nat. Rev. Immunol. 10, 210-215.

Tsukumo, D., Carvalho-Filho, M., Carvalheira, J., Prada, P. C., Hirabara, S., Schenka, A., et al. (2007). Loss-of-function mutation in Toll-like receptor 4 prevents diet-induced obesity and insulin resistance. Diabetes 56, 1986-1998.

Tuncman, G., Hirosumi, J., Solinas, G., Chang, L., Karin, M., and Hotamisligil, G. S. (2006). Functional in vivo interactions between JNK1 and JNK2 isoforms in obesity and insulin resistance. Proc. Natl. Acad. Sci. U.S.A. 103, 10741-10746.

Ueki, K., Kadowaki, T., and Kahn, C. R. (2005). Role of suppressors of cytokine signaling SOCS-1 and SOCS- 3 in hepatic steatosis and the metabolic syndrome. Hepatol. Res. 33, 185-192.

Vallerie, S. N., Furuhashi, M., Fucho, R., and Hotamisligil, G. S. (2008). A predominant role for parenchymal c-Jun amino terminal kinase (JNK) in the regulation of systemic insulin sensitivity. PLoS ONE 3:e3151. doi: 10.1371/journal.pone.0003151

Vandanmagsar, B., Youm, Y. H., Ravussin, A., Galgani, J. E., Stadler, K., Mynatt, R. L., et al. (2011). The NLRP3 inflammasome instigates obesity-induced inflammation and insulin resistance. Nat. Med. 17, 179-188.

van Diepen, J. A., Wong, M. C., Guigas, B., Bos, J., Stienstra, R., Hodson, L., et al. (2011). Hepatocyte-specific IKK-beta activation enhances VLDL-triglyceride production in APOE$^{\star} 3$-Leiden mice. J. Lipid Res. 52, 942-950.

Vijay-Kumar, M., Aitken, J., Carvalho, F., Cullender, T., Mwangi, S., Srinivasan, S., et al. (2010). Metabolic syndrome and altered gut microbiota in mice lacking Toll-like receptor 5. Science 328, 228-231.

Wen, H., Gris, D., Lei, Y., Jha, S., Zhang, L., Huang, M. T., et al. (2011). Fatty acid-induced NLRP3-ASC inflammasome activation interferes with insulin signaling. Nat. Immunol. 12, 408-415.

Wood, I. S., de Heredia, F. P., Wang, B., and Trayhurn, P. (2009). Cellular hypoxia and adipose tissue dysfunction in obesity. Proc. Nutr. Soc. 68 , 370-377.

Wunderlich, F. T., Luedde, T., Singer, S., Schmidt-Supprian, M., Baumgartl, J., Schirmacher, P., et al. (2008). Hepatic NF-kappa B essential modulator deficiency prevents obesityinduced insulin resistance but synergizes with high-fat feeding in tumorigenesis. Proc. Natl. Acad. Sci. U.S.A. 105, 1297-1302.

$\mathrm{Xu}, \mathrm{C} .$, Bailly-Maitre, B., and Reed, J. C. (2005). Endoplasmic reticulum stress: cell life and death decisions. J. Clin. Invest. 115, 2656-2664.

Yang, R., and Trevillyan, J. M. (2008). c-Jun N-terminal kinase pathways in diabetes. Int. J. Biochem. Cell Biol. 40, 2702-2706.

Ye, D., Li, F., Lam, K., Li, H., Jia, W., Wang, Y., et al. (2012). Tolllike receptor-4 mediates obesityinduced non-alcoholic steatohepatitis through activation of X-box binding protein-1 in mice. Gut 61, 1058-1067.

Yuan, M., Konstantopoulos, N., Lee, J., Hansen, L., Li, Z. W., Karin, M. et al. (2001). Reversal of obesityand diet-induced insulin resistance with salicylates or targeted disruption of Ikkbeta. Science 293, 1673-1677.

Zabolotny, J. M., Kim, Y. B., Welsh, L. A., Kershaw, E. E., Neel, B. G., and Kahn, B. B. (2008). Proteintyrosine phosphatase $1 \mathrm{~B}$ expression is induced by inflammation in vivo. J. Biol. Chem. 283, 14230-14241.

Zadjali, F., Santana-Farre, R. Vesterlund, M., Carow, B., Mirecki-Garrido, M., HernandezHernandez, I., et al. (2012). SOCS2 deletion protects against hepatic steatosis but worsens insulin resistance in high-fat-diet-fed mice. FASEB J. 26, 3282-3291.

Zhang, X., Xu, A., Chung, S. K., Cresser, J. H., Sweeney, G., Wong, R. L., et al.
(2011). Selective inactivation of cJun NH2-terminal kinase in adipose tissue protects against diet-induced obesity and improves insulin sensitivity in both liver and skeletal muscle in mice. Diabetes 60, 486-495.

Zhang, X., Zhang, G., Zhang, H., Karin, M., Bai, H., and Cai, D. (2008). Hypothalamic IKKbeta/NF-kappaB and ER stress link overnutrition to energy imbalance and obesity. Cell 135, 61-73.

Zhao, L., Hu, P., Zhou, Y., Purohit, J., and Hwang, D. (2011). NOD1 activation induces proinflammatory gene expression and insulin resistance in 3T3-L1 adipocytes. Am. J. Physiol. Endocrinol. Metab. 301, E587-E598.

Zhou, R., Tardivel, A., Thorens, B., Choi, I., and Tschopp, J. (2010) Thioredoxin-interacting protein links oxidative stress to inflammasome activation. Nat. Immunol. 11, 136-140.

Conflict of Interest Statement: The authors declare that the research was conducted in the absence of any commercial or financial relationships that could be construed as a potential conflict of interest.

Received: 29 November 2012; accepted: 19 December 2012; published online: 08 January 2013.

Citation: Tanti J-F, Ceppo F, Jager $J$ and Berthou F (2013) Implication of inflammatory signaling pathways in obesity-induced insulin resistance. Front. Endocrin. 3:181. doi: 10.3389/fendo. 2012.00181

This article was submitted to Frontiers in Diabetes, a specialty of Frontiers in Endocrinology.

Copyright (C) 2013 Tanti, Ceppo, Jager and Berthou. This is an open-access article distributed under the terms of the Creative Commons Attribution License, which permits use, distribution and reproduction in other forums, provided the original authors and source are credited and subject to any copyright notices concerning any third-party graphics etc. 